\title{
Columnar Vertical Profile (CVP) Methodology for Validating Polarimetric Radar Retrievals in Ice Using In Situ Aircraft Measurements
}

\author{
Amanda M. Murphy, ${ }^{\mathrm{a}}$ Alexander Ryzhkov, And Pengfei Zhang \\ Cooperative Institute for Mesoscale Meteorological Studies, University of Oklahoma, and NOAA/OAR/National Severe \\ Storms Laboratory, Norman, Oklahoma
}

(Manuscript received 24 January 2020, in final form 3 July 2020)

\begin{abstract}
A novel way to process polarimetric radar data collected via plan position indicator (PPI) scans and display those data in a time-height format is introduced. The columnar vertical profile (CVP) methodology uses radar data collected via multiple elevation scans, limited to data within a set region in range and azimuth relative to the radar, to create vertical profiles of polarimetric radar data representative of that limited region in space. This technique is compared to others existing in the literature, and various applications are discussed. Polarimetric ice microphysical retrievals are performed on CVPs created within the stratiform rain region of two mesoscale convective systems sampled during two field campaigns, where CVPs follow the track of research aircraft. Aircraft in situ data are collocated to microphysical retrieval data, and the accuracy of these retrievals is tested against other retrieval techniques in the literature.
\end{abstract}

\section{Introduction}

The utility of polarimetric weather radar for enhancing understanding of various meteorological phenomena dates back over three decades. Polarimetry is particularly useful for understanding the microphysical structure of precipitation in the absence of in situ measurements and inferring microphysical processes within observed precipitation. Polarimetry has been utilized in applications such as hydrometeor classification algorithms (e.g., Straka and Zrnić 1993; Straka 1996; Zrnić and Ryzhkov 1999; Liu and Chandrasekar 2000; Straka et al. 2000; Zrnić et al. 2001; Lim et al. 2005; Park et al. 2009; Dolan and Rutledge 2009; Dolan et al. 2013; Bechini and Chandrasekar 2015), tornado detection via tornadic debris signature detection (e.g., Ryzhkov et al. 2002, 2005c; Kumjian and Ryzhkov 2008; Van Den Broeke and Jauernic 2014; Snyder and Ryzhkov 2015), and quantitative precipitation estimation (e.g., Sachidananda and Zrnić 1987; Jameson 1991; Ryzhkov and Zrnić 1996; Brandes et al. 2002; Ryzhkov et al. 2005b; Maki et al. 2005; Matrosov et al. 2006; Tabary et al. 2011; Matrosov et al. 2013; Thompson

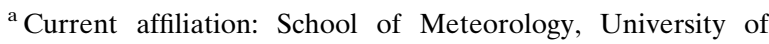
Oklahoma, Norman, Oklahoma.
}

Corresponding author: Amanda M. Murphy, amanda.murphy@ ou.edu et al. 2018). Additionally, these data can be used qualitatively to identify "polarimetric fingerprints" (Kumjian 2012; Ryzhkov and Zrnić 2019) that hint at microphysical processes such as size sorting, aggregation, melting, and refreezing. These processes can be useful to identify when trying to reproduce precipitation within a modeling framework. With the completion of the United States' WSR-88D network upgrade to dual-polarization capabilities in 2013, opportunities abound to further use polarimetry to study a wide variety of precipitation structures and weather systems.

One complication with using WSR-88D data to infer microphysical processes in various precipitating systems is that the data are collected in plan position indicator (PPI) mode. For examining cloud microphysical processes and drop or snow size distribution evolution with depth in the cloud, the most desirable radar data would be data collected at a fixed azimuth and changing elevation [a range-height indicator (RHI) scan]. Seeing as PPIs collect radar data at a fixed elevation and changing azimuth, these data do not provide a clear profile of radar returns with height in the cloud. Therefore, as described in Ryzhkov et al. (2016), this scanning strategy is not conducive for investigations into microphysical processes aloft, or comparison to other data that are collected and presented in a time-height format. As previously mentioned, a preferable scanning strategy would consist of RHI scans, which provide a vertical 
"slice" of the atmosphere. These scans are not performed operationally, however, and reconstructed RHIs are typically too poor quality to be able to deduce finescale polarimetric features within precipitation. The incentive exists, therefore, for a method to reconstruct vertical profiles of radar data from PPI scans, which would facilitate easy comparison of radar data to data collected in a time-height manner such as in situ microphysical data.

A number of methods have been proposed and utilized in literature to reconstruct vertical profiles of radar data from PPI scans. One of these techniques was the quasi-vertical profile (QVP) technique (Ryzhkov et al. 2016), which creates a vertical profile of polarimetric radar data by averaging data over all $360^{\circ}$ around the radar at a single high elevation angle. QVPs have been used in a number of studies to connect observed or modeled microphysical processes with what is observed by radar (e.g., Van Den Broeke et al. 2017; Bukovčić et al. 2017; Kumjian and Lombardo 2017; Sulia and Kumjian 2017; Ryzhkov et al. 2017; Trömel et al. 2017; Griffin et al. 2018). This technique performs well in regions where precipitation is horizontally homogeneous, but uncertainty is introduced into the profiles when the precipitation is horizontally heterogeneous (Kumjian et al. 2013; Trömel et al. 2014; Ryzhkov et al. 2016). Tobin and Kumjian (2017) expanded on the QVP technique by developing the "range-defined" QVP (RD-QVP), which creates vertical profiles by combining QVPs at multiple elevations using an inverse distance weighting technique, with each QVP created using data only within $50 \mathrm{~km}$ of the radar. These are used primarily to investigate polarimetric signatures near the surface and close to the radar. Like the QVP, this technique is also radarcentric and averages data over a fairly large sector, decreasing its utility in heterogeneous precipitation, and when regions of interest are further from the radar. Other techniques, such as the enhanced vertical profile and slanted vertical profile (EVP and SVP, respectively; Bukovčić et al. 2017) allow for investigation of precipitation over smaller sectors and farther from the radar. However, SVPs source data from a single elevation and over a large range interval, resulting in a profile that is shallow and can struggle when precipitation is horizontally heterogeneous, and EVPs use median values of polarimetric variables (instead of means, as in the other methods) and a limited number of azimuths around the point of interest, both allowing for noise to greatly influence the final product. Other methods, such as GridRad (Homeyer and Bowman 2017), take data from multiple radars to make Cartesian maps of radar data at regular intervals in height, from which vertical profiles can easily be made. However, the vertical resolution of such data is often too coarse to examine finescale polarimetric or microphysical processes.

The microphysical structure of mesoscale convective systems (MCSs), particularly of their trailing stratiform regions, is an important area of study. A number of field campaigns have focused on gaining a deeper understanding of the microphysical structure of MCSs, including the Bow Echo and MCV Experiment (BAMEX; Davis et al. 2004), the Midlatitude Convective Clouds Experiment (MC3E; Jensen et al. 2016), and the Plains Elevated Convection At Night field project (PECAN; Geerts et al. 2017). Such campaigns and studies typically focus on the trailing stratiform region, as that region is much safer to fly and collect measurements in than in the leading convective line. Of particular interest are regions such as the melting layer (ML) and dendritic growth layer (DGL), a layer from approximately $-12^{\circ}$ to $-18^{\circ} \mathrm{C}$ where particles can grow quickly via diffusion and often grow in a highly anisotropic manner (e.g., Bailey and Hallett 2009).

A thorough understanding of the ice microphysical properties of the stratiform rain region of MCSs is important for two main reasons. The first is that such regions typically contain high concentrations of very small ice crystals, especially between regions from $-10^{\circ}$ to $-50^{\circ} \mathrm{C}$ (e.g., Fridlind et al. 2015). This creates a serious risk for commercial aviation due to possible engine power loss and damage from aircraft engines ingesting ice crystals in regions of low reflectivity $(Z<20 \mathrm{~dB} Z)$ where such aircraft do not expect a high concentration of ice. The values of ice water content (IWC) in the high ice water content (HIWC) regions can be as high as $3-4 \mathrm{~g} \mathrm{~m}^{-3}$, with typical median volume diameters of ice particles less than $0.5 \mathrm{~mm}$ (Fridlind et al. 2015; Strapp et al. 2016; Leroy et al. 2017). The second reason why understanding the ice microphysical properties of these regions is imperative is that modeling studies have yet to fully capture the structure of the stratiform rain region of MCSs, especially at high altitudes. Studies such as Fan et al. (2015), Fridlind et al. (2017), and Han et al. (2019) modeled the 20 May 2011 MC3E MCS, and found that predictions of mean volume diameter of ice particles, ice number and mass concentrations, and rain rates deviated by up to an order of magnitude from measured values. Stanford et al. (2017) did a similar analysis for a tropical MCS near Darwin, Australia, and showed that modeling attempts highly overestimated the size of particles and reflectivity in the higher regions of the cloud. All of these studies show a deficiency in the community's ability to model microphysical processes within, and properties of, such stratiform rain, and a need for additional details about the ice microphysical properties of MCSs. 
The majority of the information collected about the microphysical structure of MCSs has been done via the use of in situ instrumentation, especially aircraft in situ probes. Aircraft in situ data, including IWC, total number concentration per unit volume $\left(N_{t}\right)$, and mean volume diameter $\left(D_{m}\right)$ provide valuable information about the properties of hydrometeors observed within a given volume. However, collecting information in this manner is incredibly costly, primarily done only during large field campaigns, and is only collected on a thin path where the aircraft flies. Microphysical retrievals using radar data, particularly polarimetric radar data, can provide information on the qualitative and quantitative ice microphysical properties of precipitation in a more cost-effective manner. These retrievals can be used for estimating the microphysical structure of precipitation on the order of every $5 \mathrm{~min}$, and can do so across the continental United States due to the extensive nature of the WSR-88D network.

For decades, radar reflectivity was the primary radar variable utilized for estimating IWC. A number of studies have suggested various $Z$-IWC relations in clouds composed of ice and snow, including Sassen (1987), Atlas et al. (1995), Liu and Illingworth (2000), Hogan et al. (2006), Delanoe et al. (2014), Heymsfield et al. (2005, 2016), Protat et al. (2016), Matrosov et al. (2019), and Skofronick-Jackson et al. (2019). Relations that depend solely on radar reflectivity can prove unreliable because such a single parameter is unable to capture the variability of the size distributions of ice and snow particles, their habits, and their densities. To help rectify this problem, polarimetric radar data have shown promise for being the basis of quantitative retrievals of ice microphysical properties, as polarimetry can provide further information on the size, shape, and orientation of hydrometeors within a volume beyond what limited information is offered with single-polarization radar (e.g., Zhang 2017; Ryzhkov and Zrnić 2019).

However, polarimetric retrievals of ice microphysical properties remain largely unexplored. Pioneering work was done in the late twentieth century performing ice microphysical retrievals using polarimetric radar data by Vivekanandan et al. (1994), who suggested using specific differential phase $K_{\mathrm{DP}}$ to estimate IWC. Because $K_{\mathrm{DP}}$ depends on the particle aspect ratio and orientation whereas IWC does not, the use of $K_{\mathrm{DP}}$ requires the a priori knowledge of the particles' shapes and orientations, which is not ideal. More recently, Aydin and Tang (1997) and Ryzhkov et al. $(1998,2018)$ have estimated ice particle properties using $K_{\mathrm{DP}}$ and $Z_{\mathrm{DR}}$, whose ratio is practically not affected by the variability of particles' aspect ratios and orientations. Bukovčić et al. (2018) also derived polarimetric radar relations to quantify snow properties using $Z$ and $K_{\mathrm{DP}}$, showing significant improvement in estimates compared to results from $Z$-based retrieval methods.

To evaluate these retrieval methods, polarimetric radar data must be collocated in time and space to aircraft in situ data, and ice microphysical retrievals be performed on these radar data in order to compare radar retrieved microphysical quantities to in situ measured quantities. Nguyen et al. (2019) recently compared aircraft in situ measurements to polarimetric retrievals of IWC in tropical MCSs, using a side-pointing X-band radar mounted on the aircraft. They compared retrievals that used only $K_{\mathrm{DP}}$ to those that used both $K_{\mathrm{DP}}$ and $Z_{\mathrm{DR}}$, as well as comparing polarimetric retrievals to experimentally fitted $Z$-IWC retrievals. They found that the polarimetric retrievals were far superior, and that including $Z_{\mathrm{DR}}$ in these retrievals reduced root-meansquare error from 0.52 to $0.49 \mathrm{~g} \mathrm{~m}^{-3}$ using data from seven campaign flights. To expand this type of methodology to operational and/or ground based radar, this requires the development of a method to process radar data collected in a PPI format and present it in a time-height manner, focusing on a small region in the horizontal.

Here we introduce the columnar vertical profile (CVP) technique, a technique that creates vertical profiles of polarimetric radar data using data from within a set sector in range and azimuth. By using multiple elevation angles and sourcing data from sectors typically defined as spanning $20 \mathrm{~km}$ radially and $20^{\circ}$ azimuthally around a point of interest, vertical profiles of polarimetric radar data of the full depth of a precipitating system can be constructed from a limited sector of data. In this analysis, first, two MCS case studies from two different field campaigns are introduced. Next, the CVP technique is described in detail and compared to both QVPs and GridRad (Bowman and Homeyer 2017) vertical profiles. A method to collocate the CVP data to the aircraft location is discussed, and microphysical retrievals to be performed on these data are introduced. Microphysical retrievals are then performed on both MCS cases, retrieval data from one of these cases are collocated with in situ data, and in situ measurements are compared to these collocated retrievals.

\section{Data and instrumentation}

\section{a. 20 May 2011}

The first case of interest is the 20 May 2011 MCS sampled during the MC3E field campaign. The MC3E campaign focused on obtaining measurements of convective clouds to both improve scientific understanding 

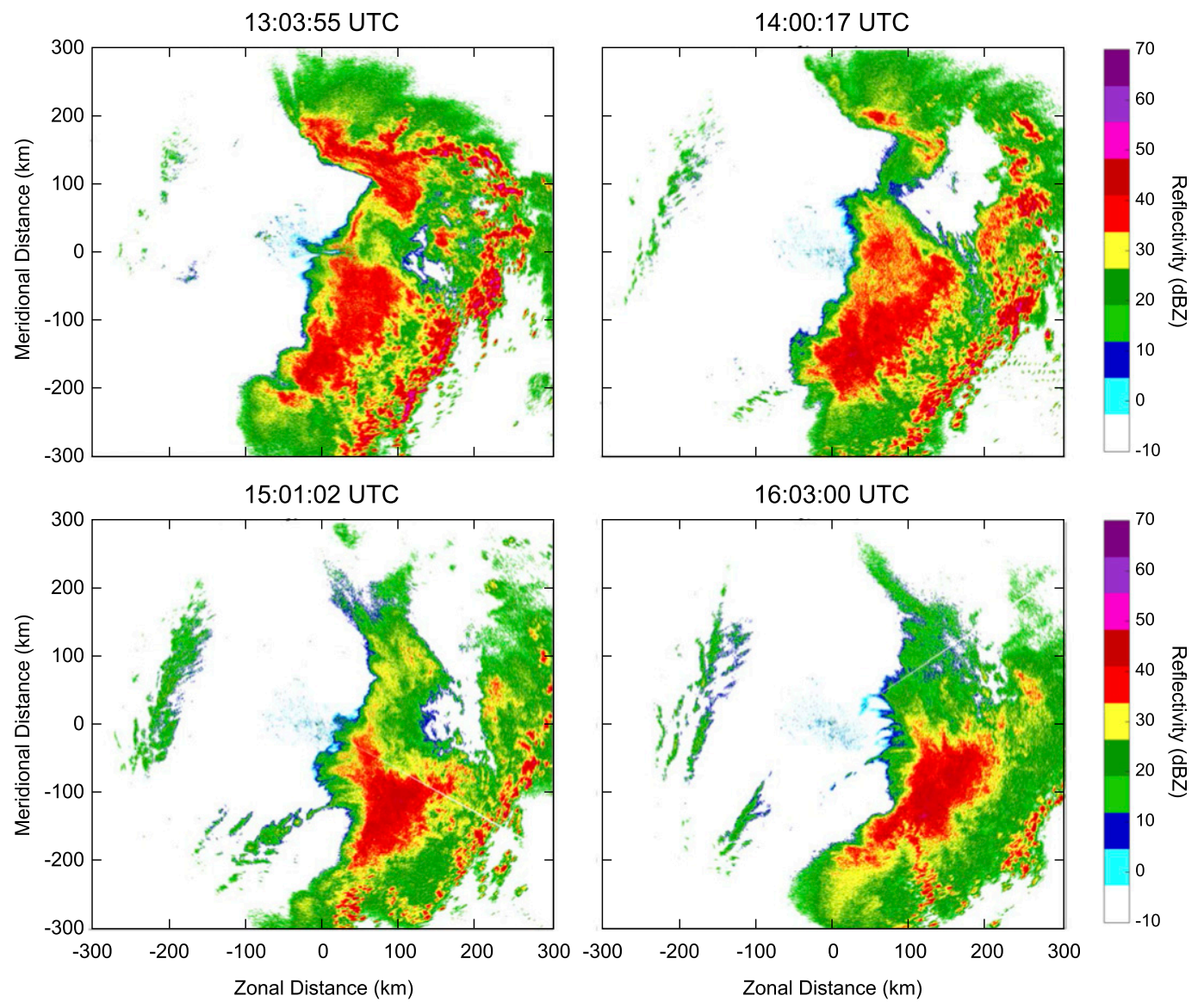

FIG. 1. PPI images of radar reflectivity (dBZ) collected at the $0.5^{\circ}$ elevation angle by the KVNX radar from 1300 to 1600 UTC. Images were selected at approximately 1-h intervals, with specific times of data collection listed above each panel.

of convective processes and utilize this knowledge to improve representation of convection in models. Based out of the DOE ARM Southern Great Plains Central Facility (SGP-CF) in north-central Oklahoma, both airborne and ground-based instruments were utilized to observe MCSs (Jensen et al. 2016, see their Fig. 1). The 20 May case was a particularly successful case for the campaign, with data collected on this day analyzed in a number of different studies (e.g., van Lier-Walqui et al. 2016; Fridlind et al. 2017; Marinescu et al. 2017; Han et al. 2019). Figure 1 shows PPIs of reflectivity from the lowest elevation scans of the MCS on that day. The convective line developed a robust stratiform region by 1000 UTC as it approached central Oklahoma, which persisted as the system propagated eastward over the Vance Air Force Base, Oklahoma (KVNX) WSR-88D. The system decayed into disorganized convection embedded in stratiform after 2000 UTC over northern Arkansas and southern Missouri. The archetypal structure of the MCS, the persistence of its stratiform region, and its path directly over the MC3E observing domain makes this a particularly attractive case to study.
During MC3E, the University of North Dakota (UND) Cessna Citation II aircraft housed all of the in situ microphysical instrumentation. The goal was to sample icephase hydrometeors, so flights focused primarily on the region between the ML and cloud top. Both the 2D cloud imaging probe (2D-C) and the high-volume particle spectrometer, version 3 (HVPS), were mounted on the aircraft, measuring cloud and precipitation particle spectra, respectively. The data were processed using the University of Illinois/Oklahoma Optical Array Probe (OAP) Processing Software (UIOOPS; McFarquhar et al. 2018). UIOOPS outputs information on the morphology of individual particles and PSDs, as well as estimates of bulk extinction, mass weighted terminal velocity, and IWC. Calculations of IWC herein used the Baker and Lawson (2006) cross-sectional mass-area relation.

\section{b. 6 July 2015}

Another case with a robust dataset is the 6 July 2015 MCS sampled during the PECAN field campaign. The PECAN experiment utilized more mobile assets than 

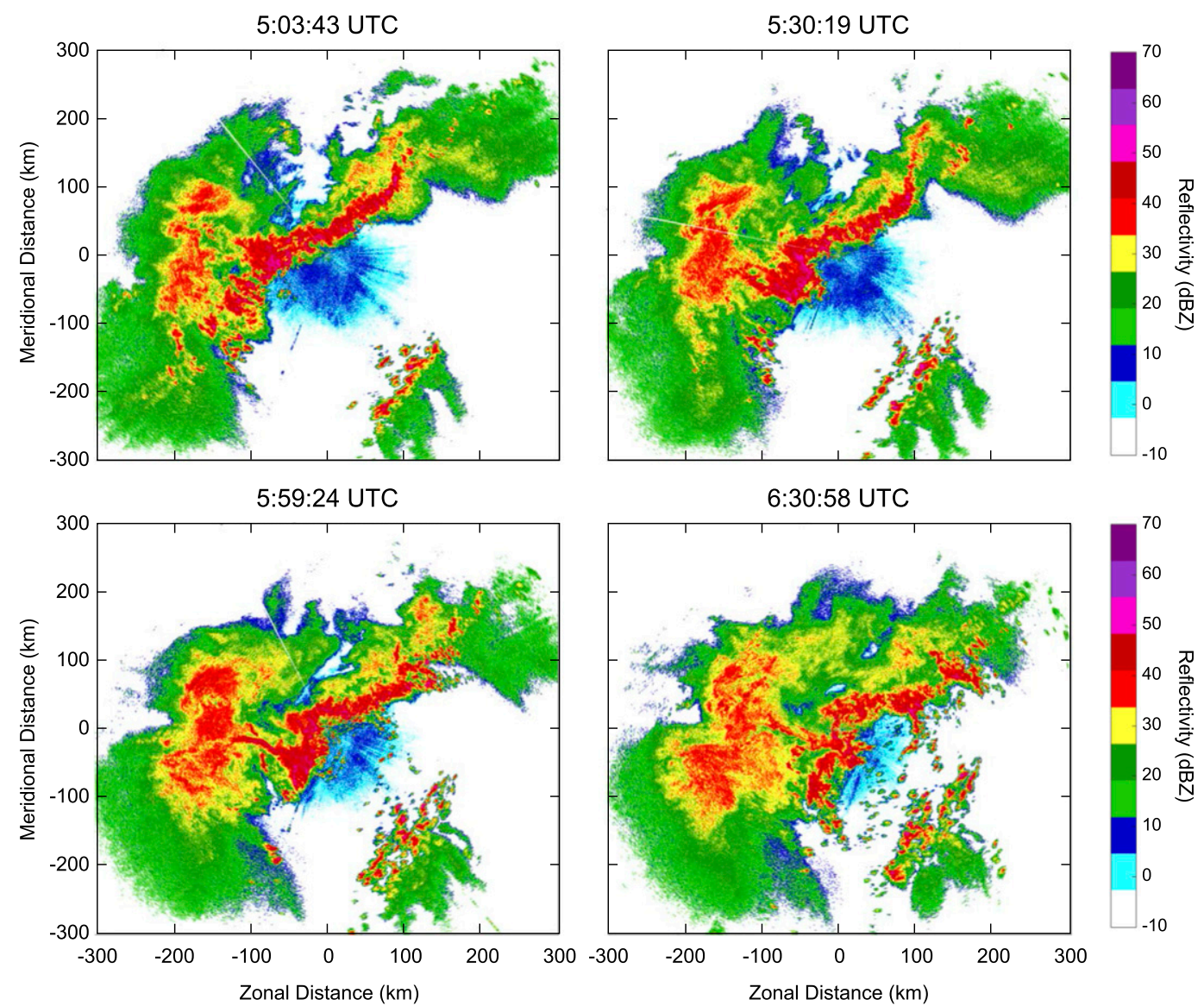

FIG. 2. PPI images of radar reflectivity ( $\mathrm{dBZ}$ ) collected at the $0.5^{\circ}$ elevation angle by the KFSD radar from 0500 to 0630 UTC. Images were selected at approximately half-hour intervals, with specific times of data collection listed above each panel.

MC3E, sampling convective systems longitudinally from Colorado to Indiana, and latitudinally from north Texas to North Dakota (Geerts et al. 2017, see their Fig. 1b). The PECAN experiment aimed "to better understand nocturnal mesoscale convective systems and their relationship with the stable boundary layer, the low-level jet, and atmospheric bores" (Geerts et al. 2017). Figure 2 shows PPIs of reflectivity from the lowest elevation scans of the MCS on that day. Stratiform precipitation began to develop behind an existing convective line around 0500 UTC on that day, and persisted as the convection began to decay. The precipitation passed over the Sioux Falls, South Dakota (KFSD), WSR-88D from approximately 0500-0900 UTC before progressing off to the ENE and dissipating.

During PECAN, the NOAA P-3 aircraft housed all of the in situ microphysical instrumentation, concentrating on the study of MCS dynamics and microphysics. Whereas the 20 May 2011 flight focused on the region between the ML and cloud top, the 6 July 2015 flight focused on making passes through the ML, and collected little data in temperature regions at or below $-10^{\circ} \mathrm{C}$. As is explained below, ice microphysical retrievals perform best at colder temperatures. Therefore, no in situ data from the 6 July 2015 case will be used to compare to ice microphysical retrievals.

\section{Methodology \\ a. CVP methodology}

Similar to aforementioned techniques, CVPs provide a finescale view of the vertical structure of precipitation by providing a simple and effective way to process polarimetric data collected in PPI format and view it in a time-height format. Whereas QVPs source radar data from the full range and azimuth scanned by a radar at a single elevation, CVPs source data within a set sector in range and azimuth and use multiple radar elevation scans performed during one volume scan to construct a vertical profile. Selecting specific data in this way allows for examination of polarimetric signatures from a 


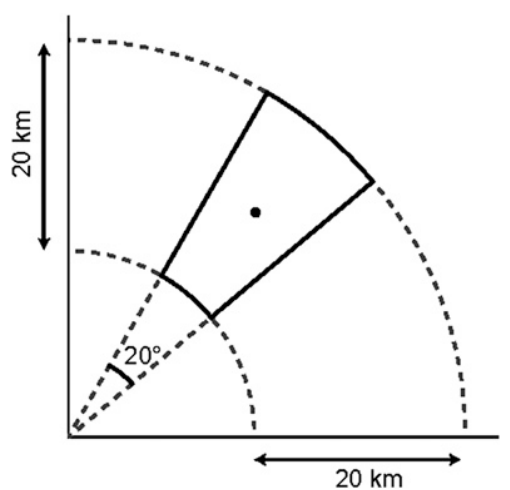

FIG. 3. Plan view of a CVP sector (outlined in solid lines), spanning $20 \mathrm{~km}$ in range and $20^{\circ}$ in azimuth. The CVP center is represented by a dot in the middle of the sector.

smaller region in space, which is particularly useful when the precipitation around the radar is horizontally heterogeneous.

To create a CVP, first, a specific location in range and azimuth from the radar is chosen for the center of the analysis. Next, a sector over which data will be sourced is chosen, defined by a given distance upradial and downradial, and azimuth clockwise and counterclockwise from the CVP center. In analyses herein, this sector spans $20 \mathrm{~km}$ in range and $20^{\circ}$ in azimuth - specifically, $10 \mathrm{~km}$ up- and downradial, and $10^{\circ}$ clockwise and counterclockwise from the CVP center. Figure 3 shows a plan view of an arbitrary CVP sector. The choice of sector size balances 1) sourcing as much data as possible for averaging and projection to the CVP center, and 2) limiting analyses to a small region of space to avoid contamination from local heterogeneities in the polarimetric data. For most cases of predominantly stratiform precipitation, a sector of $20 \mathrm{~km}$ in range and $20^{\circ}$ in azimuth proves to balance these factors well. The sector can be made larger (smaller) for precipitation with less (more) horizontal heterogeneities.

For CVPs, because only data collected within a designated sector are used, a single elevation scan cannot provide enough data to construct a full vertical profile. Therefore, data from multiple elevation angles must be used. Once a full volume scan is performed, data that are collected from each elevation scan within the boundaries of the analysis sector are averaged azimuthally. The averaged data, existing at various distances along the radial (and therefore varying heights), are projected along the horizontal to the center location of the CVP, resulting in a column of data at the CVP center that are irregularly spaced with height. Intermediate elevation angles are defined as (imaginary) angles exactly in between a given elevation angle and the elevation angles directly above and below (e.g., the intermediate elevation angle for

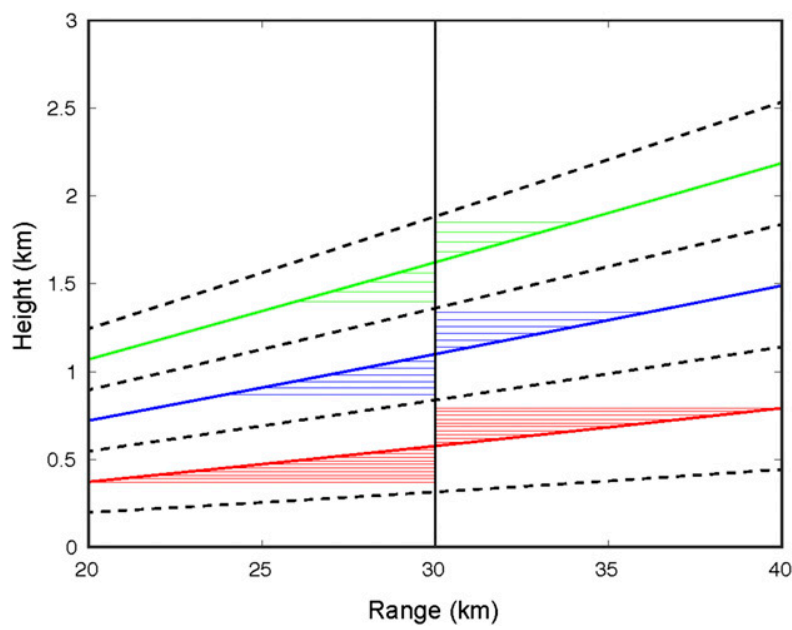

FIG. 4. Visualization of how data are projected from different elevation angles to the CVP center from a sector spanning $20 \mathrm{~km}$ in range, centered at $30 \mathrm{~km}$ from the radar. Darker lines represent data collected at $1^{\circ}$ (red), $2^{\circ}$ (blue), and $3^{\circ}$ (green) elevations, and lighter lines represent the native horizontal planes on which the data are projected. Dashed lines represent intermediate elevation angles of $0.5^{\circ}, 1.5^{\circ}, 2.5^{\circ}$, and $3.5^{\circ}$. For visual simplicity, the figure suggests data are collected at $1-\mathrm{km}$ range resolution; WSR-88D data are actually collected at $250-\mathrm{m}$ range resolution.

$1^{\circ}$ and $2^{\circ}$ elevations would be $\left.1.5^{\circ}\right)$. A restriction in projection is placed such that data cannot be projected to the CVP center from a given elevation scan at heights below the height of the lower intermediate elevation angle at the CVP center, or above the height of the higher intermediate elevation angle at the CVP center. Figure 4 illustrates this, showing how data from subsequent elevation scans are projected to the CVP center, including these limits on projection placed by intermediate elevation angles.

This data projection technique preferentially sources data that are collected closer to the CVP center in range over data collected farther from the CVP center. However, limiting data projection by these intermediate elevation angles does artificially reduce the size of the CVP sector with height. By not allowing for overlapping projection of data from two subsequent elevation scans, it also reduces the number of data points processed, therefore resulting in slightly lowered statistical accuracy. This restriction can be loosened in other studies where statistical accuracy of the polarimetric data and large CVP sector aloft are deemed more important than using data that are collected closer to the CVP center at a given height. In addition, the scheme slightly skews the data collection, by not explicitly requiring the number of projected points from upradial of the CVP center to be equal to the number of points projected from downradial of the center. Sensitivity studies were performed examining 
the mean ground range of all data points projected to the CVP center, using all operational VCPs and examining CVP center locations out to $100 \mathrm{~km}$ from the radar. The mean location of points projected to the CVP center deviates no more than $1.3 \%$ from the prescribed center location, a displacement error which is small and can be neglected given other possible sources of uncertainty in the CVP algorithm.

As mentioned previously, once projected horizontally to the location of the CVP center, the data are not regularly spaced in height. An increase in the slope of the radar beam as the radar scans higher in elevation creates a decrease in data density in the vertical with height (see Fig. 4). To create a distribution of data in the vertical that are evenly spaced with height, a Cressman averaging technique is employed (Cressman 1959). This technique creates an evenly spaced array of data in the vertical by searching for all data within a specified vertical distance from a given height, and interpolating those data to that height via weighted averaging. A Cressman radius of influence of $100 \mathrm{~m}$ is typically used, meaning that the algorithm will search vertically up and down $100 \mathrm{~m}$ for data to interpolate to a given height. While the Cressman averaging technique and weighted interpolation of data to a regular grid often fills data gaps due to its averaging in the vertical, it can still allow for gaps in data if, for a given vertical location, there are no radar data within the vertical distance of the Cressman radius of influence above or below that location. Cressman averaging is typically done every $50 \mathrm{~m}$ from 0 to $15 \mathrm{~km}$. CVPs herein show profiles of reflectivity $Z$, differential reflectivity $Z_{\mathrm{DR}}$, correlation coefficient $\rho_{\mathrm{hv}}$, and specific differential phase $K_{\mathrm{DP}}$, with $K_{\mathrm{DP}}$ processed as in Griffin et al. (2018). CVPs of differential phase $\Phi_{\mathrm{DP}}$ can also be created. As with QVPs, for cases where the radar experienced a $Z_{\mathrm{DR}}$ bias, CVPs of $Z_{\mathrm{DR}}$ are manually calibrated such that values just above the ML are approximately 0.2-0.25 dB (Ryzhkov and Zrnić 1998; Ryzhkov et al. 2005a). Cressman averaging is done on $Z$ and $Z_{\mathrm{DR}}$ in logarithmic units.

For CVPs centered far from the radar, the distance between successive elevation scans in the vertical can cause gaps in the CVP. The distance from the radar at which a CVP begins to have these gaps depends on the choice of the Cressman radius of influence, the radar scanning strategy, and the range over which the CVP sector spans. Herein, we limit CVPs to within $100 \mathrm{~km}$ of the radar. Figure 5 shows CVPs of $Z$ created at various distances from the radar in a widespread stratiform precipitation event on 7 February 2019. This stratiform precipitation was sampled by the KCLE WSR-88D using VCP 215. Examination of these plots shows that, at radial distances beyond $100 \mathrm{~km}$, gaps in the vertical significantly degrade the quality of the CVP. Further investigation needs to be done to determine the maximum distance in range from the radar CVPs can be created with radars of different wavelengths.

\section{b. Comparison to GridRad technique}

Another recently developed technique to examine radar data and vertical profiles of radar data across the United States is the GridRad technique (Bowman and Homeyer 2017). GridRad data are data sourced from 125 S-band NEXRAD National Weather Service (NWS) radars (Crum and Alberty 1993) and merged together to create a three-dimensional, high-resolution dataset of radar data covering most of the contiguous United States. In publicly available GridRad data, NEXRAD level II data from multiple radar sites are merged and gridded to a regular, high-resolution $\left(0.02^{\circ}\right.$ longitude $\times$ $0.02^{\circ}$ latitude $\times 1 \mathrm{~km}$ altitude) grid. The data for this particular study differ slightly in that the vertical resolution of the data is $500 \mathrm{~m}$ from 1 to $7 \mathrm{~km}$, providing greater detail of radar characteristics of precipitation in lower levels. GridRad data shown herein are at 1-min temporal resolution, and only $Z$ is shown for the 20 May 2011 case. Due to how data from all WSR-88Ds are merged to create GridRad data, polarimetric radar data are only available for cases occurring after the completion of the entire WSR-88D network's upgrade to dual-polarization capabilities in 2013.

GridRad has horizontal resolution of about $2 \mathrm{~km}$ and vertical resolution of $0.5-1 \mathrm{~km}$. This is a useful product for modelers to represent composite plots of radar variables in a convenient Cartesian grid over large areas. This product has most value in convective parts of storms, due to how its fine horizontal resolution can resolve individual convective cells. However, it is not optimal for polarimetric investigations of stratiform parts of precipitation for two main reasons: its poor vertical resolution, which is not sufficient to resolve the finescale structure of the ML or reliably estimate its height and depth; and large statistical errors in the estimates of polarimetric radar variables which require much more aggressive spatial averaging.

\section{1) Vertical RESOLUTION}

The melting layer, appearing as a "bright band" of radar reflectivity, has a thickness commonly varying between 0.2 and $0.6 \mathrm{~km}$ and cannot be well resolved in a grid with vertical resolution of $1 \mathrm{~km}$. For GridRad data, as described in detail in Homeyer and Bowman (2017), the value of a radar variable $\left(Z, Z_{\mathrm{DR}}, \rho_{\mathrm{hv}}\right.$, or $\left.K_{\mathrm{DP}}\right)$ in a grid cell is estimated via weighted averaging of all bin values on the rays enclosed in a $2 \mathrm{~km} \times 2 \mathrm{~km} \times 1 \mathrm{~km}$ box. This averaging is done using data from all radars within 

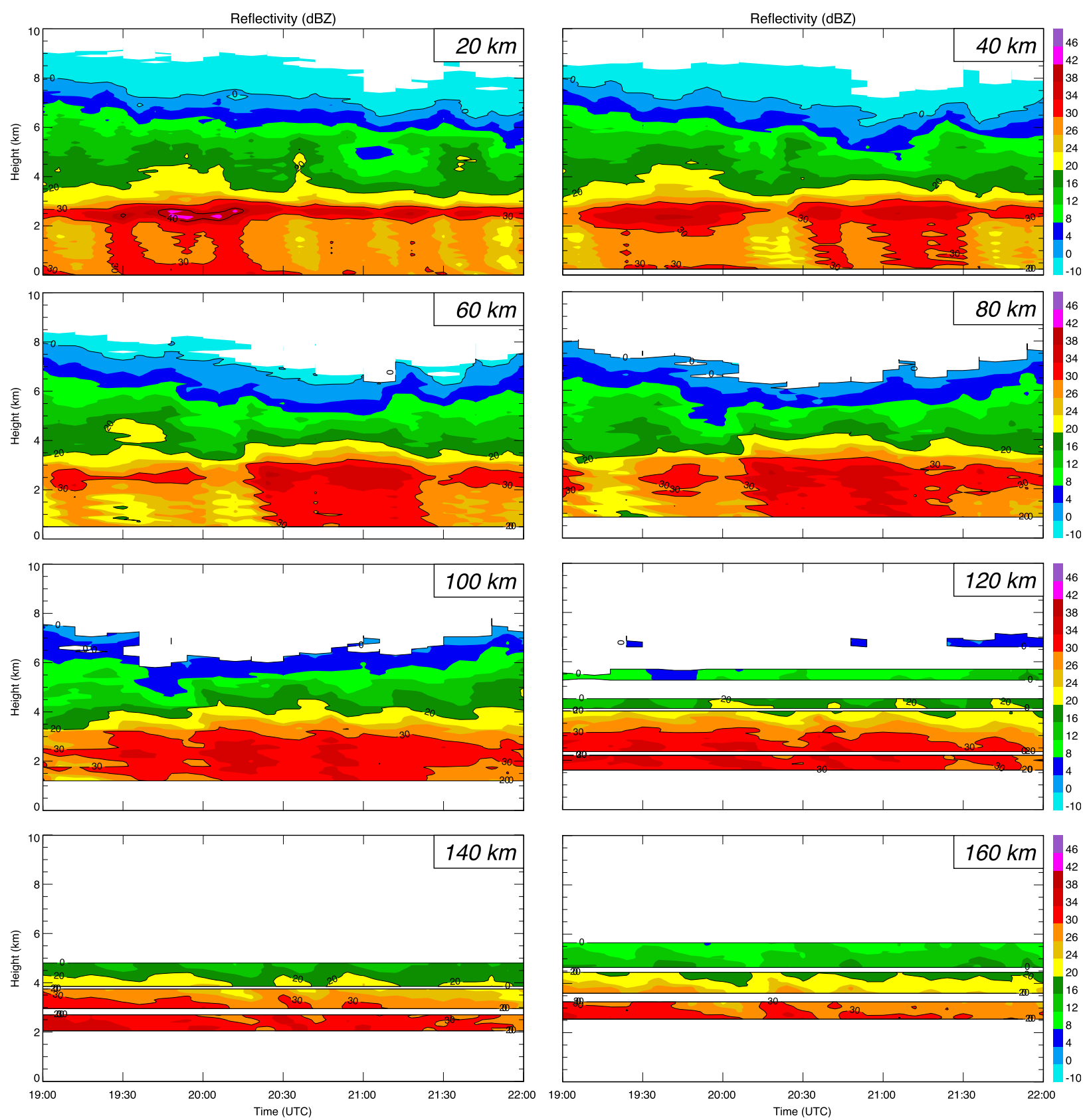

FIG. 5. CVPs of $Z$ sampled by the KCLE radar on 7 Feb 2019. CVPs are centered at an azimuth of $225^{\circ}$ and at ranges from 20 to $160 \mathrm{~km}$ from the radar, increasing in 20-km increments. Ranges are listed in the top right of each panel. The KCLE radar was operating in VCP 215 during this time period.

$300 \mathrm{~km}$ of the grid cell. With a range gate of $0.25 \mathrm{~km}$, this means that nine values are averaged for each ray regardless of the location of the bin and its height in the grid box. In comparison, the CVP method takes a much larger number of bins along the ray (if, for example, a radial extent of $20 \mathrm{~km}$ for the CVP sector is selected) and computes the height of every bin. A simple modeling example of how the CVP and GridRad techniques resolve the ML shows that this results in a much better representation of the vertical profiles of the radar variables within the ML.

Consider a simple model of the intrinsic profile of radar reflectivity $Z$ shown in Fig. 6a. Herein, we allow for overlapping of the radar beams (as mentioned in the discussion surrounding Fig. 4). If the ML in Fig. 6a is observed with a WSR-88D utilizing a standard VCP 
(a)

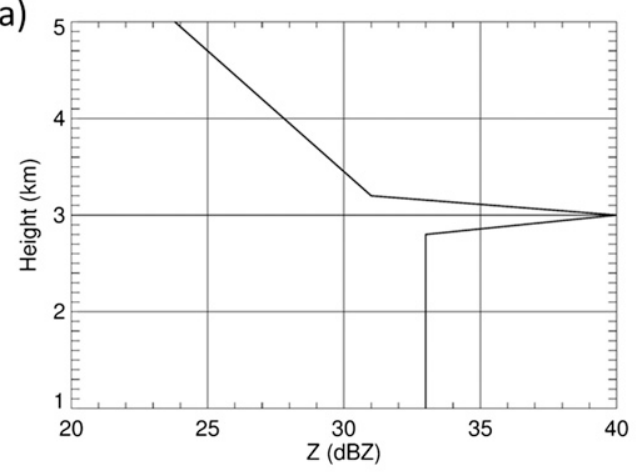

(c)

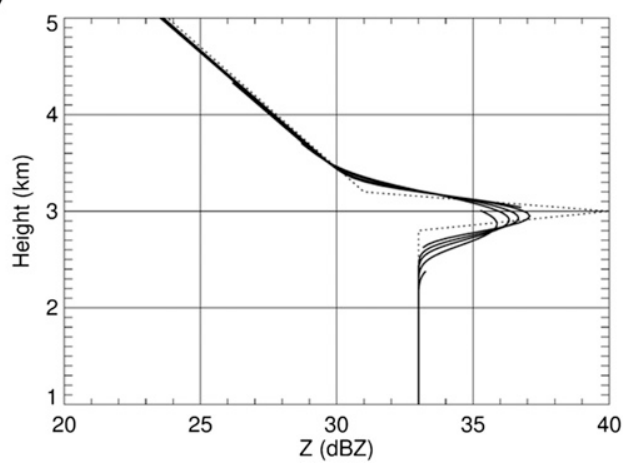

(b)

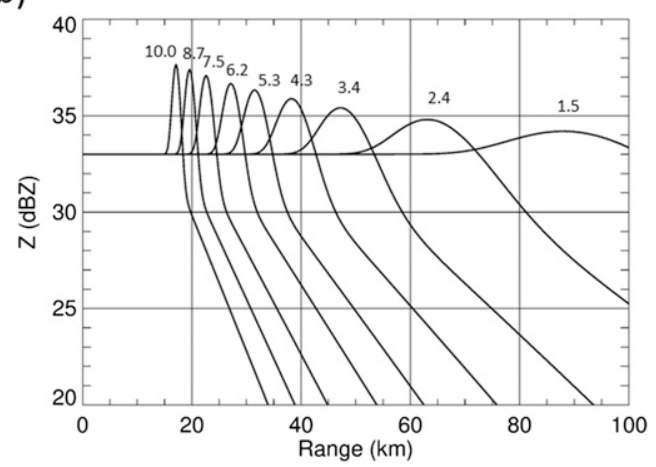

(d)

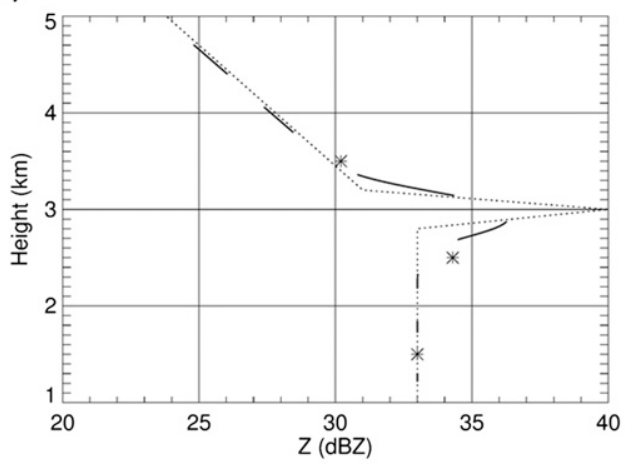

FIG. 6. (a) Intrinsic vertical profile of $Z$ through the ML; (b) model radial profiles of $Z$ measured by the radar at various antenna elevations; (c) segments of the vertical profile of $Z$ retrieved from a CVP, using data at elevations denoted in (b); and (d) segments of the vertical profile of $Z$ used by GridRad. Asterisks denote $Z$ values obtained in the $1-\mathrm{km}$ height intervals by GridRad. The intrinsic profile of $Z$ shown in (a) is overlaid as a dotted line in (c) and (d).

11 scanning pattern with elevation angles at $0.5^{\circ}, 1.5^{\circ}$, $2.4^{\circ}, 3.4^{\circ}, 4.3^{\circ}, 5.3^{\circ}, 6.2^{\circ}, 7.5^{\circ}, 8.7^{\circ}, 10.0^{\circ}, 12.0^{\circ}, 14.0^{\circ}$, $16.7^{\circ}$, and $19.5^{\circ}$, then radial profiles of $Z$ at elevation angles from $1.5^{\circ}$ to $10.0^{\circ}$ have the shape illustrated in Fig. 6b. Here, horizontally homogeneous precipitation is assumed, and the effects of beam broadening with an antenna beamwidth of $1^{\circ}$ are taken into account.

Using these data, vertical profiles of $Z$ can be constructed using both the CVP and GridRad techniques. Herein we consider constructing a vertical profile of $Z$ at a location $30 \mathrm{~km}$ from the radar where the width of the radar beam is about $0.5 \mathrm{~km}$, and a CVP sector that is $20 \mathrm{~km}$ in radial extent. Parts of the vertical profile of $Z$ retrieved from the range gates between 20 and $40 \mathrm{~km}$ at various elevation angles according to the CVP methodology are displayed in Fig. 6c. It is evident that some of these parts reproduce the bright band and the height of its center quite well. Of course, the maximal value of $Z$ in the middle of the bright band is about $3 \mathrm{~dB}$ lower than its "true" maximum, an inevitable effect of beam broadening. The corresponding parts of the $Z$ profile obtained from GridRad are shown in Fig. 6d. These pieces are much shorter because only the gates within a range interval of $2 \mathrm{~km}$ (the horizontal size of each grid box) are utilized, compared to a range interval of $20 \mathrm{~km}$ as in Fig. 6c. Additionally, the GridRad routine implies simple averaging of the corresponding data within $1 \mathrm{~km}$ height intervals, which results in three average values of $Z$ (33.0, 34.3, and $30.2 \mathrm{~dB} Z$ ) corresponding to the median heights of $1.5,2.5$, and $3.5 \mathrm{~km}$ (shown with asterisks in the plot). Thus, the CVP algorithm reproduces the shape and parameters of the bright band in much more detail, although both methods utilize the same raw radar data. It is interesting that the effective vertical resolution of the $Z$ profile obtained from the CVP is significantly better than the width of the radar beam $(0.5 \mathrm{~km})$ at a range of $30 \mathrm{~km}$.

\section{2) Statistical ACCURACY}

Improvement in the statistical accuracy of the estimates of polarimetric radar variables is a primary motivation for developing both QVPs and CVPs. Ensuring reliable measurements of $K_{\mathrm{DP}}$ is of great importance, as it is a key variable for quantification of ice and snow 
(Ryzhkov and Zrnić 2019). The existing scheme for processing differential phase data on the WSR-88Ds produces an estimate of $K_{\mathrm{DP}}$ with radial resolution of $6 \mathrm{~km}$ and standard deviation of $0.11^{\circ} \mathrm{km}^{-1}$ in areas where $Z<40 \mathrm{~dB} Z$ (Ryzhkov and Zrnić 2019). At S band, $K_{\mathrm{DP}}$ in ice and snow is typically below $0.1^{\circ} \mathrm{km}^{-1}$, and $K_{\mathrm{DP}}$ data look quite erratic and noisy in the cold parts of clouds above the ML. There are four to eight independent samples of the $K_{\mathrm{DP}}$ data in the GridRad resolution box of $2 \mathrm{~km} \times 2 \mathrm{~km} \times 1 \mathrm{~km}$ located at $30 \mathrm{~km}$ from the radar if the azimuthal resolution of the radar is equal to $1^{\circ}$ (at four azimuths and one or two elevations). Note that the $K_{\mathrm{DP}}$ samples at nine successive gates within a $2-\mathrm{km}$ radial interval are not independent because the radial resolution of the $K_{\mathrm{DP}}$ estimate is $6 \mathrm{~km}$ for $Z<40 \mathrm{~dB} Z$.

The CVP methodology uses $K_{\mathrm{DP}}$ averaging over a much larger spatial domain (typically $20 \mathrm{~km}$ by $20^{\circ}$ in stratiform parts of the storm). Hence the number of independent samples of $K_{\mathrm{DP}}$ along the radial is 3 times larger and along the azimuth is 5 times larger than in GridRad; i.e., the standard deviation of the $K_{\mathrm{DP}}$ estimate is reduced by the factor $\sqrt{3 \times 5} \approx 3$.9. This allows for measuring of $K_{\mathrm{DP}}$ in ice and snow to an accuracy of $0.01^{\circ} \mathrm{km}^{-1}$.

\section{3) COMPARISON OF TECHNIQUES WITHIN MCS STRATIFORM PRECIPITATION}

Figure 7 shows a comparison of vertical profiles of $Z$ from 1000 to 1330 UTC collected by the KVNX radar created using the GridRad and CVP techniques. Vertical profiles using both techniques are created using sectors centered at $30 \mathrm{~km}$ in range and $90^{\circ}$ in azimuth. The CVP sector is $20 \mathrm{~km}$ in range and $20^{\circ}$ in azimuth, and GridRad profiles show the average of data collected within a $9 \times 9$ grid box surrounding the center point. Averaging the GridRad data in this sense mimics the azimuthal averaging of radar data performed during the creation of CVPs. During this time, an MCS was in the vicinity of the radar and passed through the sectors of the GridRad vertical profile and the CVP.

In both the GridRad vertical profile and the CVP, the leading convective line, transition zone, and trailing stratiform region of the MCS (e.g., Houze et al. 1989) are clearly visible. Both the GridRad vertical profile and CVP agree on the location in altitude of maximum $Z$ (indicative of the ML) and approximate cloud top height, but the GridRad vertical profile underestimates the magnitude of the ML signature in $Z$ and the vertical extent of the highest $Z$ values in the convection. Visually, the CVP has superior resolution in the upper portions of the cloud as previously shown in Fig. 6, allowing for a more finescale view of polarimetric radar
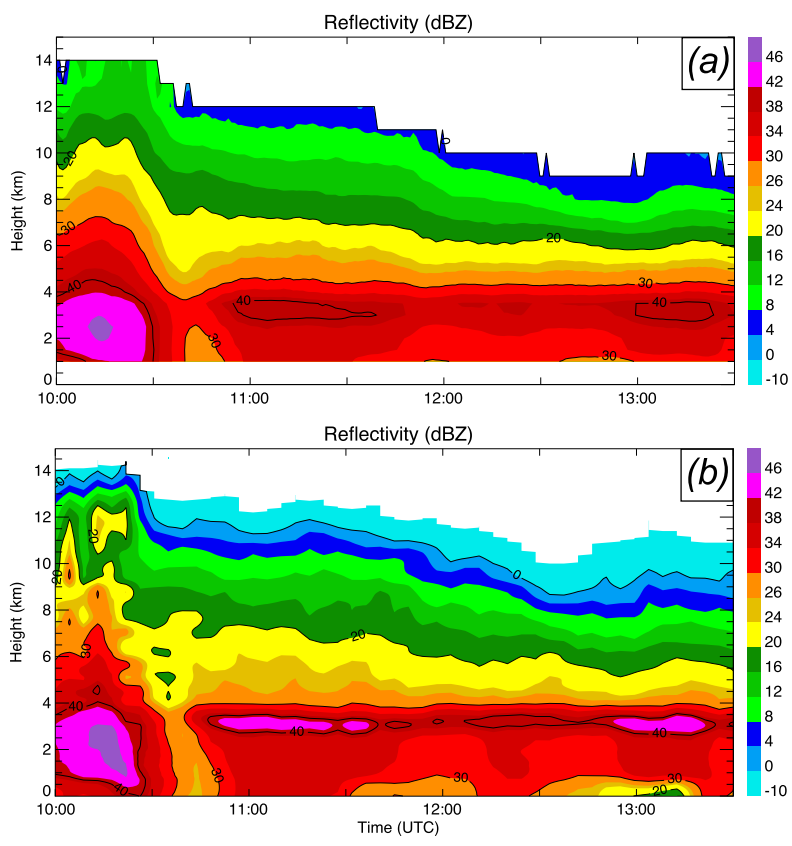

FIG. 7. A comparison of vertical profiles of $Z$ from 1000 to 1330 UTC collected by the KVNX radar created using the (a) GridRad and (b) CVP techniques. Vertical profiles using both techniques are created using sectors centered at $30 \mathrm{~km}$ in range and $90^{\circ}$ in azimuth. The CVP sector is $20 \mathrm{~km}$ in range and $20^{\circ}$ in azimuth, and GridRad profiles show the average of data collected within a $9 \times 9$ grid box surrounding the center point. Averaging the GridRad data in this sense mimics the azimuthal averaging of radar data performed during the creation of CVPs. During this time, an MCS was in the vicinity of the radar and passed through the sectors of the GridRad vertical profile and the CVP.

variables. For applications examining finescale horizontal structure of precipitation and requiring the use of multiple radars, GridRad is excellent and should be used. This discussion motivates simply the use of CVPs versus GridRad data when examining finescale data at high altitudes and when high statistical accuracy of the polarimetric variables is very important, for applications such as the polarimetric microphysical retrievals at high altitudes discussed herein.

\section{c. Moving and data extraction}

The ability to tailor the resultant vertical profile to a specific location in range and azimuth from the radar is another major advantage of CVPs over QVPs. The CVP technique allows for analyses of polarimetric radar signatures and the evolution of precipitation over a specific area, and can also be modified such that the CVP is centered on a different location for each successive volume scan. This moving CVP has the same sector size in range and azimuth, the same vertical data spacing after Cressman averaging, and the same Cressman radius of influence for every volume scan; it differs 

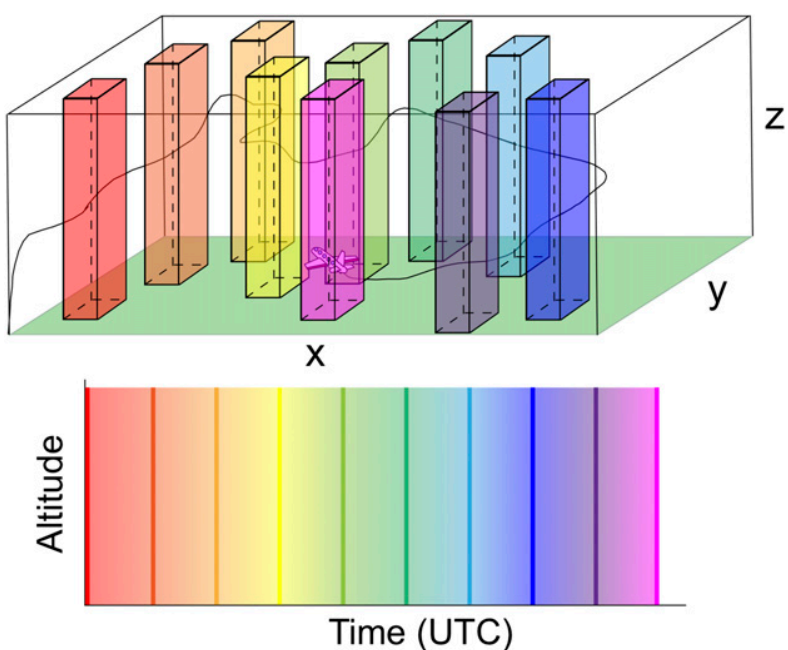

FIG. 8. A conceptual model of how a moving CVP is created following the flight path of an aircraft. (top) How data are sourced from different regions for each sequential volume scan. (bottom) How the data are then plotted in a time-by-height format.

from a stationary CVP only in the location on which it is centered. This technique can be useful for applications such as cell tracking and following the location of aircraft. Figure 8 shows a conceptual model of how a CVP can be made to move in time with the path of an aircraft. The upper panel shows a 3D model of an aircraft moving in time, with different colored columns representing the location of the CVP sector and the column from which data were sourced to create a CVP at that time. The lower panel shows how these data, collected at different locations and from sequential volume scans, are displayed in a time-height format.

Figure 9 shows a CVP moving in time, using data from the KVNX WSR-88D on 20 May 2011. The UND aircraft was flying within and on the periphery of the stratiform region of the MCS in Fig. 1, and was within the requisite $100 \mathrm{~km}$ of the KVNX radar for the entire flight, from roughly 1300 to 1700 UTC. The CVP is centered on the location of the aircraft at the recorded start time of the lowest elevation scan in each volume scan, with the bold black line on all subpanels denoting the aircraft altitude at that time. Having the CVP move in such a manner results in vertical columns of data that are representative of the region in which the aircraft is flying. Near regions of high gradients of a given polarimetric variable, zigzag-like features can be occasionally seen (e.g., around 1515 UTC on Fig. 9a). These are a result of creating a CVP where low and high values of a polarimetric variable are right next to each other, and

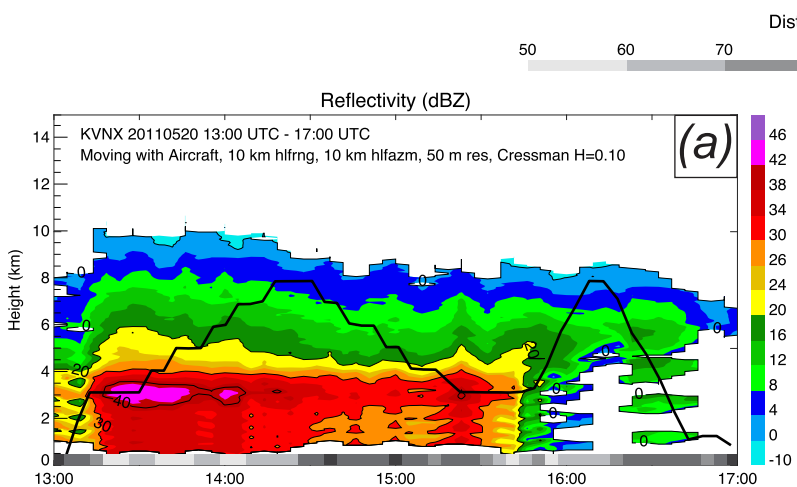

$80 \quad 90 \quad 100$
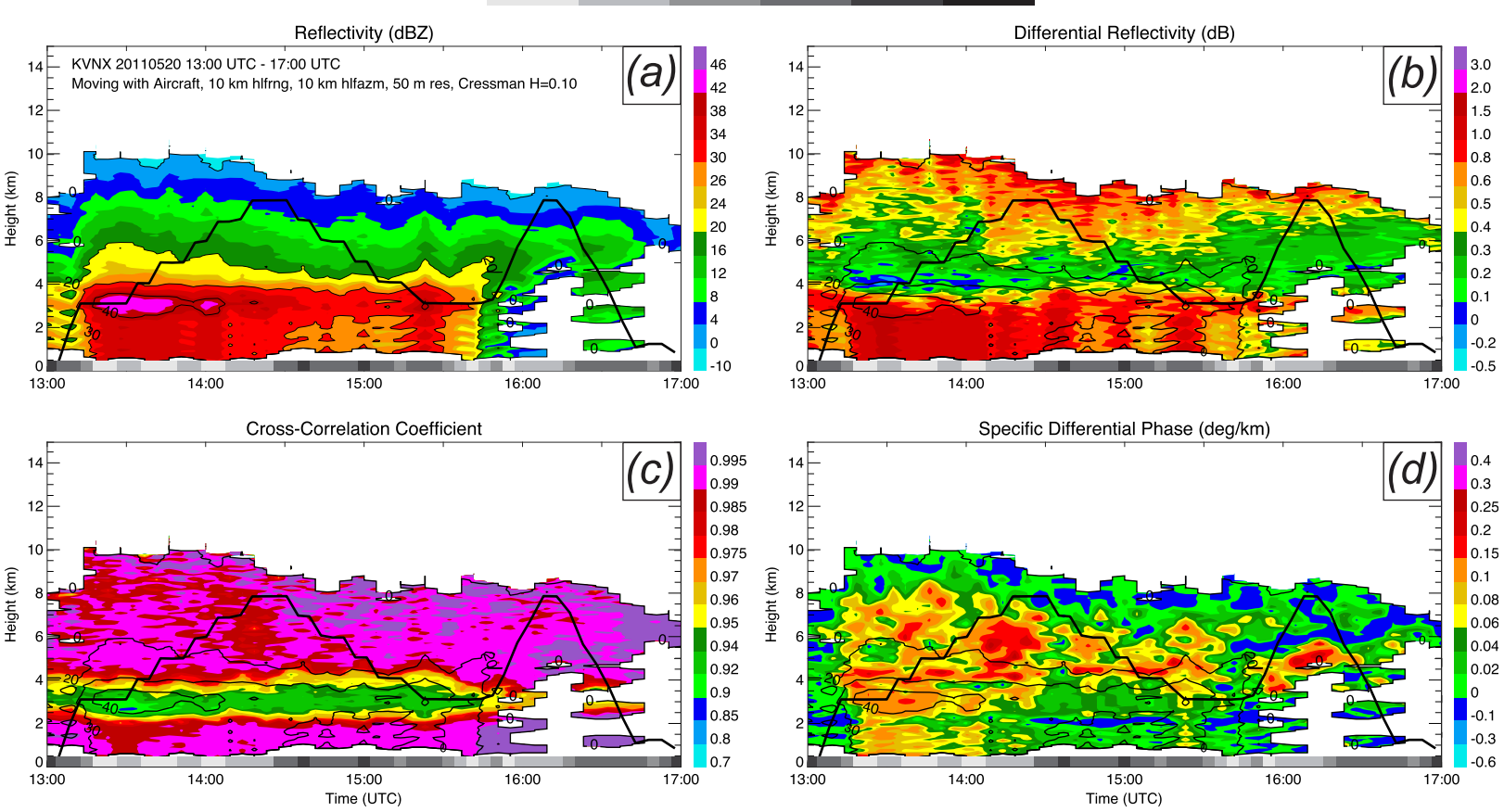

FIG. 9. Moving CVP using measurements from the KVNX radar from 1300 to 1700 UTC 20 May 2011. The CVP sector moved with the location of the research aircraft flying during the MC3E campaign. (a) $Z$, (b) $Z_{\mathrm{DR}}$, (c) $\rho_{\mathrm{hv}}$, and (d) $K_{\mathrm{DP}}$. The bold black line overlaid in each panel represents the altitude of the aircraft with time, and thin black lines represent reflectivity at $0,20,30$, and $40 \mathrm{dBZ}$. Vertical data spacing in the CVP is $50 \mathrm{~m}$, and the sector size is $20 \mathrm{~km}$ in range and $20^{\circ}$ in azimuth. Distance from the radar for each scan is denoted just above the $x$ axis on each panel. 

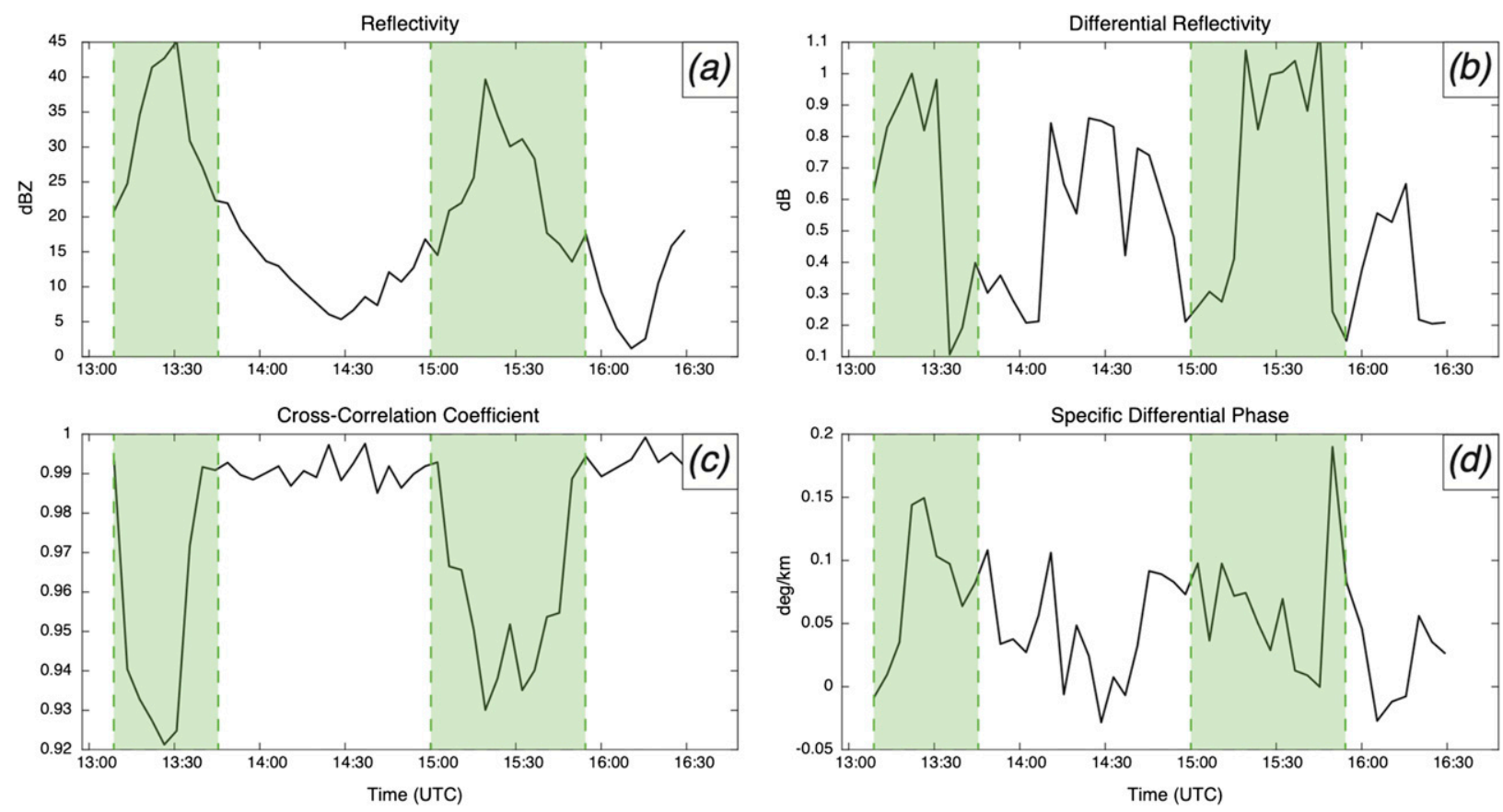

FIG. 10. Time series plots of (a) $Z$, (b) $Z_{\mathrm{DR}}$, (c) $\rho_{\mathrm{hv}}$, and (d) $K_{\mathrm{DP}}$ collocated to the aircraft location as it flew through the MCS represented in the CVP in Fig. 9. Green shaded regions represent times where the aircraft flew within or below the ML.

therefore projecting high and low values of a variable on top of each other (see Fig. 4). Such effects can be mitigated primarily by reducing the CVP sector size. Herein, we chose not to reduce the sector size to rectify this, since our focus will be above the ML where this artifact rarely appears.

After collocating the aircraft location to the CVP data in the horizontal, for accurate comparison of radar retrievals and in situ data, these data must also be collocated in the vertical. To do so, for every full volume scan of data (and therefore every column in the CVP), the data in that column of the CVP are assumed to have been collected later in time with height, with the time of data collection increasing linearly with height from the start time of the current volume scan to the start time of the next volume scan. For Cressman averaging at every $50 \mathrm{~m}$ in the vertical, it is assumed that the data at each specific altitude are representative of the $50-\mathrm{m}$ region vertically surrounding that altitude. For collocation with aircraft data, first the aircraft's altitude is found at the assigned time for each vertical level in the CVP column. If the aircraft's altitude is within the 50-m region surrounding the CVP data at that time, then the aircraft data at that time and CVP data at that level are said to be collocated. Figure 10 shows a time series plot of polarimetric radar data extracted from the flight path shown on the CVP in Fig. 9, with green shaded regions representing times where the aircraft flew within or below the
ML. Comparing the values in Fig. 10 to the colors along the flight track in the corresponding panels in Fig. 9, it is evident that the technique accurately extracts radar data along the flight track, corroborating the effectiveness of this technique.

A moving CVP can also be made using data from the KFSD radar for the 6 July 2015 MCS. Figure 11 shows a moving CVP for this case, where vertical gaps in data occur when the aircraft flew beyond $100 \mathrm{~km}$ from the radar. Herein, an ML is visible in $Z$ and $\rho_{\mathrm{hv}}$, with an increase in $Z_{\mathrm{DR}}$ clearly visible below the ML, as in Fig. 9. There are also strong signatures of $K_{\mathrm{DP}}$ within the DGL (from approximately 6 to $8 \mathrm{~km}$, estimated from aircraft altitude and air temperature measurements at the bottom of the DGL, and assuming a somewhat constant lapse rate). This region of high $K_{\mathrm{DP}}$ is collocated with a region of low $Z_{\mathrm{DR}}$, which could indicate a high concentration of predominantly quasi-isometric ice (Griffin et al. 2018).

\section{d. Microphysical retrievals}

As previously mentioned, polarimetric radar data provide a wealth of information that can be used to improve existing ice microphysical retrieval algorithms and develop even more sophisticated ones. The ice microphysical retrievals used in this study were developed by Ryzhkov et al. (2018), and use $Z_{\mathrm{DP}}, Z, Z_{\mathrm{dr}}, K_{\mathrm{DP}}$, and radar wavelength $\lambda$ to estimate IWC, $N_{t}$, and $D_{m}$. 

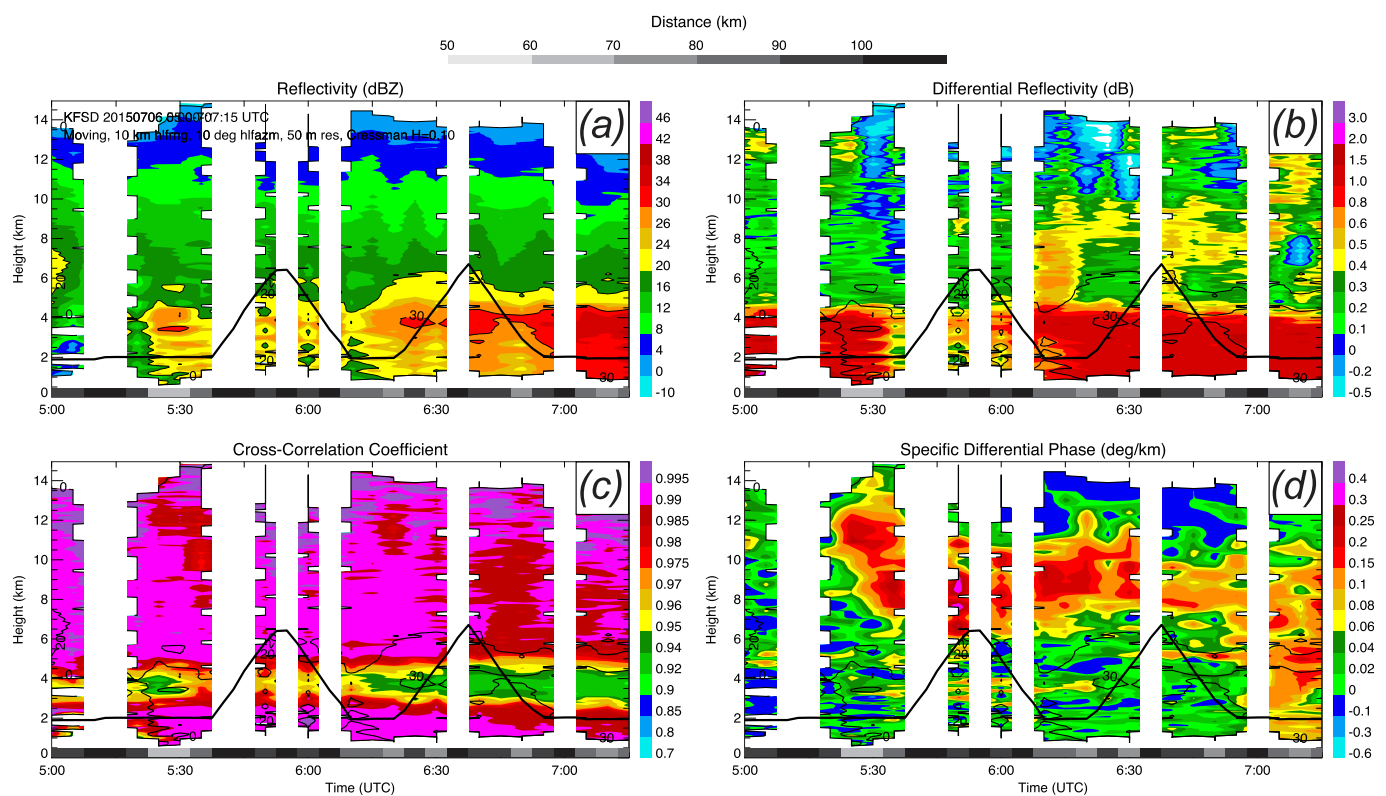

FIG. 11. Moving CVP using measurements from the KFSD radar from 0500 to 0715 UTC 6 Jul 2015. The CVP sector moved with the location of the research aircraft flying during the PECAN campaign. Plots show (a) $Z$, (b) $Z_{\mathrm{DR}}$, (c) $\rho_{\mathrm{hv}}$, and (d) $K_{\mathrm{DP}}$. The bold black line overlaid in each panel represents the altitude of the aircraft with time, and thin black lines represent reflectivity at 0,20 , and $30 \mathrm{dBZ}$. Vertical data spacing in the CVP is $50 \mathrm{~m}$, and the sector size is $20 \mathrm{~km}$ in range and $20^{\circ}$ in azimuth. Distance from the radar for each scan is denoted just above the $x$ axis in each panel.

An overview of these equations can be found in both Ryzhkov et al. (2018) and Ryzhkov and Zrnić (2019) and is concisely summarized here. The IWC is determined from the combination of $K_{\mathrm{DP}}$ and $Z_{\mathrm{DR}}$ as

$$
\mathrm{IWC} \approx 4.0 \times 10^{-3}\left(\frac{K_{\mathrm{DP}} \lambda}{1-Z_{\mathrm{dr}}^{-1}}\right),
$$

where $Z_{\mathrm{dr}}=10^{0.1 Z_{\mathrm{DR}}}, \lambda$ is the radar wavelength in $\mathrm{mm}$, IWC is expressed in $\mathrm{g} \mathrm{m}^{-3}$, and $K_{\mathrm{DP}}$ is in ${ }^{\circ} \mathrm{km}^{-1}$. Because the numerator and denominator in the right part of Eq. (1) are proportionally affected by the shape and orientation of ice particles, the estimate of IWC is immune to these factors.

The mean volume diameter $D_{m}$ (in $\mathrm{mm}$ ) can be estimated from the equation

$$
D_{m}=-0.1+2\left(\frac{Z_{\mathrm{DP}}}{K_{\mathrm{DP}} \lambda}\right)^{1 / 2}
$$

In Eq. (2), $Z_{\mathrm{DP}}=Z_{h}-Z_{v}$ is the reflectivity difference or the difference between reflectivity factors at horizontal and vertical polarizations expressed in linear scale (units of $\mathrm{mm}^{6} \mathrm{~m}^{-3}$ ). Similar to the discussion for Eq. (1), simulations of the dependence of $D_{m}$ to the second term in Eq. (2) (Ryzhkov and Zrnić 2019, their Fig. 11.10) show that the equation is largely immune to varying ice habits.
Total concentration of ice particles $N_{t}\left(\right.$ in $\left.^{-1}\right)$ is given by

$$
\log \left(N_{t}\right)=0.1 Z-2 \log \left(\frac{Z_{\mathrm{DP}}}{K_{\mathrm{DP}} \lambda}\right)-1.11
$$

where $Z$ is in $\mathrm{dB} Z$. Again, because the effects of the shape and orientation are cancelled in the ratio $Z_{\mathrm{DP}} / K_{\mathrm{DP}}$, the corresponding estimates of $N_{t}$ are immune to them. Equations (1)-(3) were derived in the Rayleigh approximation under the assumption that the density of ice particles/snowflakes is inversely proportional to their equivolume diameter (e.g., Brandes et al. 2007). The effects of non-Rayleigh or resonance scattering in dry snow are negligible at S band, and Eqs. (1)-(3) can be safely applied to the WSR-88D data herein. Details of derivation of Eqs. (1)-(3) can be found in Ryzhkov et al. (2018) and Ryzhkov and Zrnić (2019). Before calculating these microphysical quantities, data are thresholded such that retrievals are only performed for points where $Z>0 \mathrm{~dB} Z, Z_{\mathrm{DR}}>0.1 \mathrm{~dB}$, and $K_{\mathrm{DP}} \geq 0.01^{\circ} \mathrm{km}^{-1}$.

After a moving CVP is created for a particular flight and interval of time, the data at each vertical level can be ingested into Eqs. (1)-(3). Only data above the ML, objectively determined using sounding data from these field campaigns at times closest to the flight time, are used to produce estimates of $D_{m}, N_{t}$, and IWC. Microphysical data are then collocated to aircraft 
in situ data in the same manner in which CVP data and aircraft in situ data are collocated.

\section{CVP microphysical retrievals}

An estimate of the microphysical structure of precipitation in the vicinity of an aircraft can be made by performing the aforementioned microphysical retrievals on moving CVPs. These data can be plotted much like the moving CVP data, taking into account that only data above the ML are ingested into the retrieval codes. On 20 May 2011, soundings taken around the ARM SGP-CF were used to determine the altitude of the $0^{\circ} \mathrm{C}$ level before, during, and after flight times (Atmospheric Radiation Measurement 1994). The mean and median altitudes from all sites and all launch times were $3.8 \mathrm{~km}$, with $94 \%$ of soundings showing the $0^{\circ} \mathrm{C}$ level at $4.5 \mathrm{~km}$ or below. To restrict analyses to only ice particles, only data from above $4.5 \mathrm{~km}$ are used to produce estimates of $D_{m}, N_{t}$, and IWC.

Figure 12 shows microphysical retrievals performed on the MCS from 20 May 2011. Qualitatively, the stratiform precipitation contained ice particles with mean volume diameters primarily at or below $1.0 \mathrm{~mm}$, except early in the flight near the ML. Particle concentrations were on the order of $10-100 \mathrm{~L}^{-1}$, and IWC values mainly spanned from approximately 0.3 to $1.5 \mathrm{~g} \mathrm{~m}^{-3}$. Between 1300 and 1400 UTC, a signature of aggregation is visible in Figs. $12 \mathrm{a}$ and $12 \mathrm{~b}$, where $D_{m}$ increases and $N_{t}$ decreases toward the ML.

It is worth noting that some spurious values of all retrievals are obvious near the ML after 1600 UTC, in a region of low $Z$, low $Z_{\mathrm{DR}}$, and high $K_{\mathrm{DP}}$. This signature may be associated with a high concentration of small, anisotropic crystals resulting from secondary ice production (e.g., Crosier et al. 2014). For situations such as these where ice crystal shape is likely very anisotropic, the combination of $Z_{\mathrm{DR}}$ and $K_{\mathrm{DP}}$ in the microphysical retrieval equations is used to account for shape uncertainty, but is apparently unsuccessful here since values of $Z_{\mathrm{DR}}$ are so low. It is likely that pristine ice crystals are mixed with a few larger hydrometeors with a more spherical shape in this region, leading to both high $K_{\mathrm{DP}}$ and low $Z_{\mathrm{DR}}$.

Retrievals of $D_{m}$ and IWC were also performed on this same storm by Tian et al. (2016) between 1015 and 1415 UTC (see their Fig. 4), using their strictly $Z$-based retrievals. Within the stratiform rain region, they retrieved values of IWC between $0.5-1.5 \mathrm{~g} \mathrm{~m}^{-3}$ at $6 \mathrm{~km}$ and $0.2-0.6 \mathrm{~g} \mathrm{~m}^{-3}$ at $8 \mathrm{~km}$. This is in close agreement with values shown in Fig. 12, where we estimate IWC values between $0.25-1.5 \mathrm{~g} \mathrm{~m}^{-3}$ at $6 \mathrm{~km}$ and $0.1-0.8 \mathrm{~g} \mathrm{~m}^{-3}$ at $8 \mathrm{~km}$. Estimates of $D_{m}$ in the stratiform rain region at
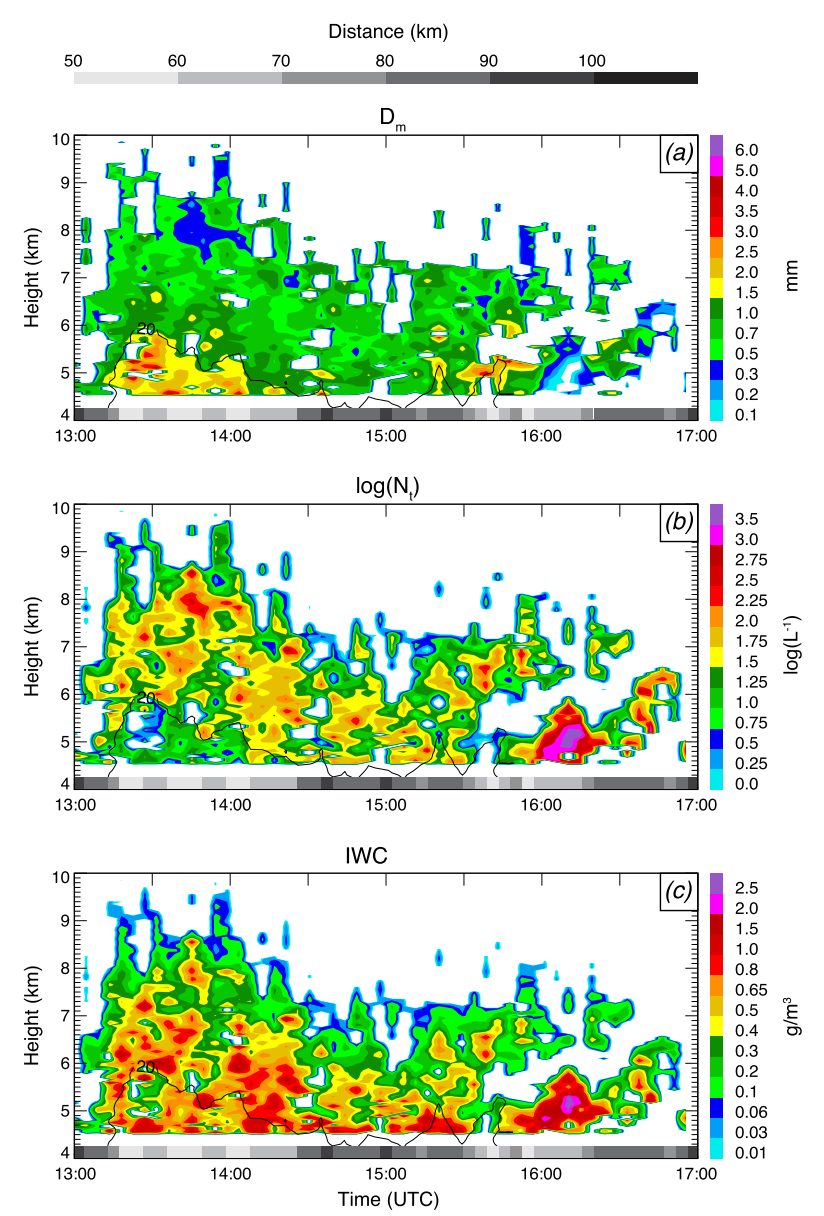

FIG. 12. Ice microphysical retrievals performed on the 20 May 2011 moving CVP. Plots show (a) $D_{m}(\mathrm{~mm}),\left(\right.$ b) $\log \left(N_{t}\right)\left[\log \left(\mathrm{L}^{-1}\right)\right]$, and (c) IWC $\left(\mathrm{g} \mathrm{m}^{-3}\right)$. Retrieval data shown herein are limited to altitudes above $4.5 \mathrm{~km}$. Thin black lines represent reflectivity at $20 \mathrm{dBZ}$. Distance from the radar for each scan is denoted just above the $x$ axis in each panel.

these altitudes differ more between the two studies, with values of $1.5-2.0 \mathrm{~mm}$ at $6 \mathrm{~km}$ and $0.75-1.75 \mathrm{~mm}$ at $8 \mathrm{~km}$ retrieved by Tian et al. (2016), whereas values in Fig. 12 range from $0.5-1.5$ and $0.3-1.0 \mathrm{~mm}$ at those two altitudes. However, they show in their Fig. 6 that their retrievals of $D_{m}$ do have a slight bias toward larger sizes when compared to in situ data, which may explain the slight bias they also show to the retrievals in Fig. 12. Figure 12 from Han et al. (2019) also shows simulations of IWC for the same case from 1235 to 1320 UTC. While their simulated values are fairly close to those retrieved herein at $6 \mathrm{~km}\left(0.4-1.1 \mathrm{~g} \mathrm{~m}^{-3}\right)$, their IWC values at higher altitudes $\left(0.3-1.2 \mathrm{~g} \mathrm{~m}^{-3}\right)$ are too large compared to the NEXRAD retrievals in that study, the IWC retrievals in Tian et al. (2016) at $8 \mathrm{~km}$, and the retrievals herein.

Figure 13 shows microphysical retrievals performed on the MCS from 6 July 2015. Soundings launched by 

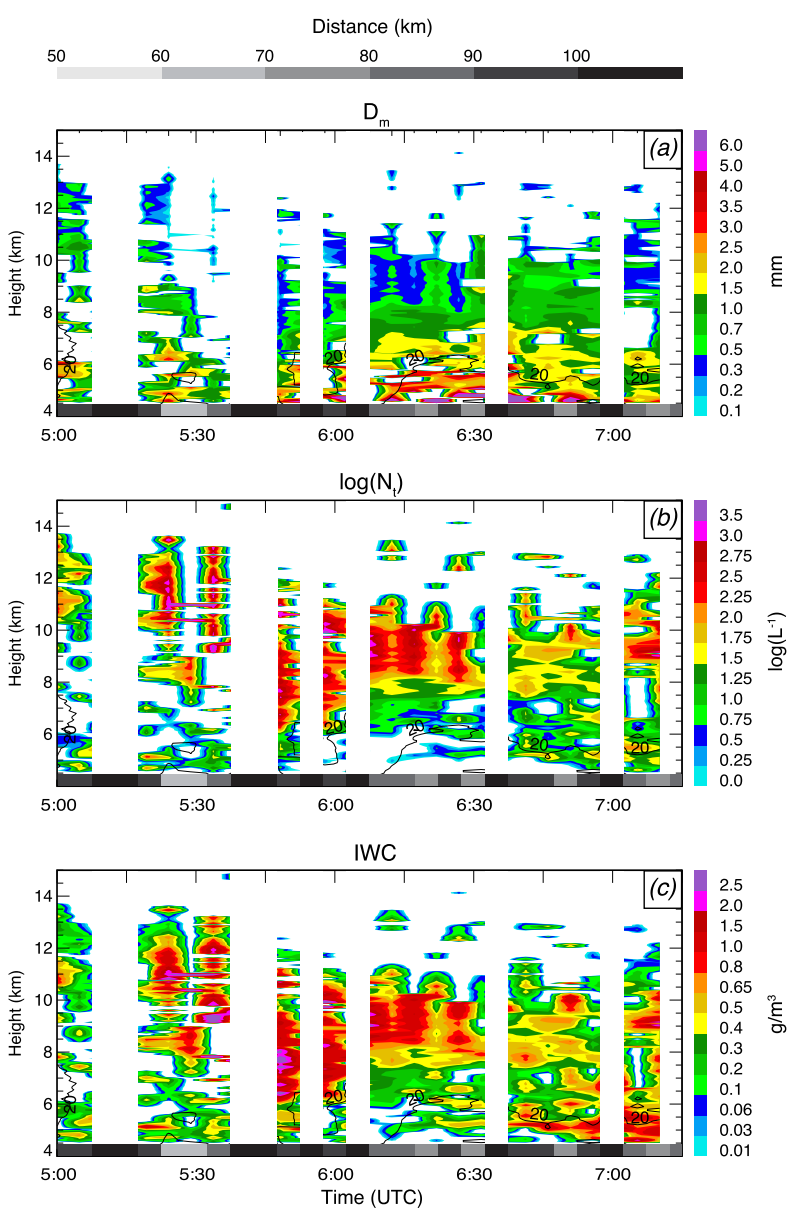

FIG. 13. Ice microphysical retrievals performed on the $6 \mathrm{Jul} 2015$ moving CVP. (a) $D_{m}(\mathrm{~mm})$, (b) $\log \left(N_{t}\right)\left[\log \left(\mathrm{L}^{-1}\right)\right]$, and (c) IWC $\left(\mathrm{g} \mathrm{m}^{-3}\right)$. Retrieval data shown herein are limited to altitudes above $4.5 \mathrm{~km}$. Thin black lines represent reflectivity at $20 \mathrm{dBZ}$. Distance from the radar for each scan is denoted just above the $x$ axis in each panel.

PECAN Mobile PECAN Integrated Sounding Array (PISA) 1 [i.e., Collaborative Lower Atmospheric Mobile Profiling System (CLAMPS); Klein et al. 2016] at 0300 and 0400 UTC show the $0^{\circ} \mathrm{C}$ isotherm at an altitude of around $4.6 \mathrm{~km}$. Therefore, only retrieval data above $4.5 \mathrm{~km}$ are shown herein. Herein, a considerable portion of the region above the ML was characterized by fairly low $Z_{\mathrm{DR}}$ values, including larger regions than in the 20 May 2011 case (blue colors and gaps in Fig. 13b). This led to more numerous gaps in the retrievals, which, along with gaps due to the aircraft flying beyond $100 \mathrm{~km}$ from the radar, somewhat inhibits interpretation. However, the limited data available do suggest a different microphysical structure than that of the 20 May 2011 MCS, with smaller $D_{m}$ values and larger $N_{t}$ and IWC values aloft in this storm. Noticeable differences between the storms on 20 May 2011 and 6 July 2015 are revealed from the comparison of their CVPs in Figs. 9 and 11. First, the radar reflectivity above the $\mathrm{ML}$ is generally lower in the second case while $K_{\mathrm{DP}}$ is higher. Second, the storm on 6 July 2015 is significantly deeper, with the temperature at its top lower than $-40^{\circ} \mathrm{C}$. These low temperatures are conducive to massive homogeneous freezing of cloud droplets in the upper parts of the storm. Indeed, the soundings from the NWS office in Aberdeen, South Dakota, at 0000 and 1200 UTC show temperatures of $-30^{\circ} \mathrm{C}$ near $10.5 \mathrm{~km}$ and $-40^{\circ} \mathrm{C}$ near $12.3 \mathrm{~km}$. Examining Fig. 11, the system's cloud top was near $14 \mathrm{~km}$, making homogeneous freezing near cloud top possible. A combination of low Z, high $K_{\mathrm{DP}}$, and considerable storm depth is indicative of high concentration of small ice with significant IWC as mentioned by Ryzhkov et al. (2018) and Ryzhkov and Zrnić (2019, their Figs. 11.15 and 11.16).

\section{Collocation to in situ data}

As mentioned previously, in the PECAN campaign, flight plans focused on making multiple passes through the ML, with limited data collection at temperatures much colder than $-10^{\circ} \mathrm{C}$ on 6 July 2015 . The ice microphysical retrievals used herein work best at cold temperatures far from the ML (Ryzhkov et al. 2018), particularly at temperature "lower than $-10^{\circ}$ to $-15^{\circ} \mathrm{C}$." For that reason, collocation of in situ data to ice microphysical retrievals herein will focus on the 20 May 2011 MC3E case, with retrieval data collocated to HVPS data.

By applying the ice microphysical retrievals to KVNX radar data (Fig. 12) and collocating those data to the aircraft in situ data, ice microphysical retrievals performed on CVP data can now be directly compared to aircraft in situ data. In this manner, the accuracy of Eqs. (1)-(3) can be tested to determine how well they are able to retrieve the microphysical properties of the stratiform rain region of a midlatitude MCS.

Figure 14 shows a direct comparison of aircraft in situ data (lines) to ice microphysical retrievals (black dots) performed on moving CVP data. Data are not shown for when the aircraft was flying below the ML, which accounts for data gaps before 1345 UTC, between approximately 1500 and 1600 UTC, and after 1630 UTC. Overall, the retrievals estimated particle size fairly well at high altitudes, with $D_{m}$ retrievals diverging from measurements primarily when the aircraft was near the ML (i.e., near gaps in the plot). Error in $N_{t}$ estimates were higher, with largest errors in retrieved values when the aircraft approached the ML around 1500 and 1600 UTC. Estimates of IWC were predominantly biased low, and, like $D_{m}$ estimates, diverged from measured values when the aircraft was near the ML. 

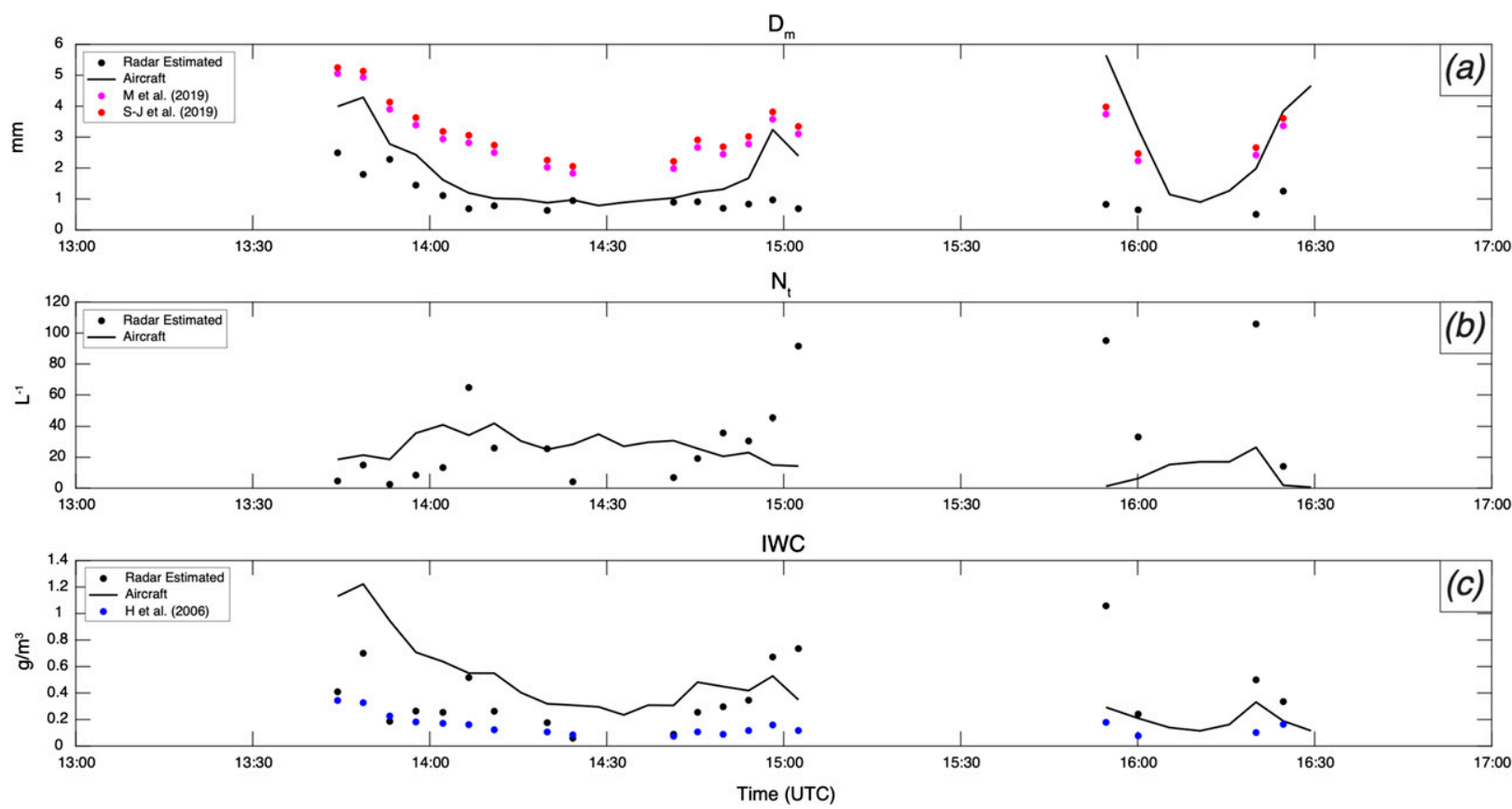

FIG. 14. Collocated aircraft in situ data (solid line) and ice microphysical retrievals of moving CVP data (dots) collected on 20 May 2011. Plots show (a) $D_{m}(\mathrm{~mm})$, (b) $N_{t}\left[\log \left(\mathrm{L}^{-1}\right)\right]$, and (c) IWC $\left(\mathrm{g} \mathrm{m}^{-3}\right)$. Additional $D_{m}$ and IWC retrievals by Skofronick-Jackson et al. (2019) [(a), red dots], Matrosov et al. (2019) [(a), magenta dots], and Hogan et al. (2006) [(c), blue dots] using collocated radar data are also shown. Retrieval data shown herein are limited to altitudes above $4.5 \mathrm{~km}$, and data collected below that level are not shown.

In addition, these data and retrievals are compared to other Z-based retrievals for both $D_{m}$ and IWC. Retrievals of $D_{m}$ were performed using the $Z-D_{m}$ relations in Skofronick-Jackson et al. (2019) (Fig. 14a, red dots) and Matrosov et al. (2019) (Fig. 14a, magenta dots). The relation from Skofronick-Jackson et al. (2019) is from their Fig. 8, where a power-law relation between $D_{m}$ (in $\mathrm{mm}$ ) and $Z$ is fit to data collected during the GPM Cold Season Precipitation Experiment (GCPEx) campaign:

$$
D_{m}=1.45 Z^{0.25}
$$

where $Z$ is in linear scale. A similar method is used to derive the relation in Matrosov et al. (2019) in their Fig. 10, where a power-law relation is derived from S-band $Z$ data and median volume diameter calculated from in situ data collected during the ISDAC campaign. Median volume diameter is converted to $D_{m}$ (in $\mathrm{mm}$ ) herein using a relation between the two from Matrosov et al. (2019):

$$
D_{m}=1.09\left(1.15 Z^{0.271}\right),
$$

where $Z$ is in linear scale. IWC retrievals are also calculated using the Hogan et al. (2006) Z-IWC relation (Fig. 14c, blue dots), using in situ temperature data as recorded during the flight:

$$
\mathrm{IWC}=10^{(0.060 Z-0.0212 T-1.92)},
$$

where IWC is in $\mathrm{g} \mathrm{m}^{-3}$, temperature $T$ is in ${ }^{\circ} \mathrm{C}$, and $Z$ is in $\mathrm{dB} Z$. The polarimetric retrievals from Ryzhkov et al. (2018) predict values closer to those measured by the HVPS probe than the other retrieval methods for a large majority of the collocated points. One notable exception is for values of $D_{m}$ when the aircraft is close to the ML around 1600 to 1630 UTC. Of course, a more rigorous evaluation of these retrieval methods will require additional cases to provide more collocated in situ data.

\section{Conclusions}

This study examined how operational weather radar data could be better used to understand the vertical structure of precipitation on an even finer scale than what is possible using QVPs, and capitalized on a rich opportunity to use in situ microphysical measurements to validate ice microphysical retrieval algorithms optimized for S-band operational weather radar data. The goal of this study was to utilize operational polarimetric radar data and polarimetric ice microphysical retrieval algorithms in conjunction with in situ aircraft data to gain a deeper understanding of the ice microphysical structure of MCSs, and determine the usefulness and effectiveness of such new ice microphysical 
retrieval algorithms and radar data processing techniques. Three primary conclusions can be drawn from the work herein:

1) The CVP methodology has emerged as a novel way to visualize operational polarimetric radar data collected by S-band WSR-88Ds. This technique is most appropriate when the CVP sector is centered at a distance less than $100 \mathrm{~km}$ from the radar, and can be altered such that the CVP center moves in time. This can be used for applications such as cell tracking or tracking of aircraft. Compared to the GridRad technique, CVPs offer greater vertical resolution, which is important for analyzing finescale polarimetric signatures in precipitation. Additionally, the smoothing of polarimetric radar data performed by CVPs is imperative for reducing noise in polarimetric radar data, particularly $K_{\mathrm{DP}}$, which can be quite noisy in regions of light to moderate precipitation.

2) Newly developed ice microphysical retrieval techniques using polarimetric radar data show promise in quantitatively estimating $D_{m}, N_{t}$, and IWC within midlatitude MCSs. Such algorithms work best in regions of high $Z_{\mathrm{DR}}$ and high $K_{\mathrm{DP}}$, such as in the DGL. Retrievals performed on the 20 May 2011 MCS suggested particles with $D_{m}$ at or below $1.0 \mathrm{~mm}$ and particle concentrations between 10 and $100 \mathrm{~L}^{-1}$, with visible signs of aggregation. On 6 July 2015, retrievals overall estimated smaller $D_{m}$ and much higher and IWC values than on 20 May 2011.

3) A method to collocate aircraft location in three dimensions and CVP data was developed and applied to match aircraft in situ data with radar microphysical retrieval data. The retrievals were compared to in situ data from the HVPS probe as well as compared to other reflectivity-based retrieval methods, and show promise in accurately estimating the microphysical structure of stratiform precipitation above the ML. To fully evaluate the accuracy of these retrievals, a much larger dataset consisting of multiple precipitation events must be considered.

Acknowledgments. The authors thank Drs. Greg McFarquhar and Wei $\mathrm{Wu}$ for providing and processing aircraft in situ data from the MC3E campaign, as well as Dr. Cameron Homeyer for providing GridRad data. The authors also thank three anonymous reviewers for their thorough, constructive, and kind remarks that helped improve this study. Funding was provided by NOAA/Office of Oceanic and Atmospheric Research under NOAA-University of Oklahoma Cooperative Agreement NA16OAR4320115, U.S. Department of Commerce, and by the DOE ASR program under
Grant DE-SC0018967. Components of this work were originally presented in the M.S. thesis of Murphy (2018).

Data availability statement. In situ microphysical data for the MC3E campaign were provided and processed by Drs. Greg McFarquhar and Wei Wu, with data processed using the University of Illinois/Oklahoma Optical Array Probe (OAP) Processing Software (UIOOPS; McFarquhar et al. 2018). GridRad data were provided and processed by Dr. Cameron Homeyer, with processing techniques outlined in Bowman and Homeyer (2017). Other radar data used to create CVPs were accessed and downloaded via NOAA NCEI (National Weather Service 1991). MC3E mobile sounding data were obtained from the Atmospheric Radiation Measurement (ARM) User Facility, a U.S. Department of Energy (DOE) Office of Science user facility managed by the Office of Biological and Environmental Research (Atmospheric Radiation Measurement 1994). PECAN mobile sounding data were provided by NCAR/EOL under the sponsorship of the National Science Foundation (https://data.eol.ucar.edu/; Klein et al. 2016).

\section{REFERENCES}

Atlas, D., S. Matrosov, A. Heymsfield, M. Chou, and D. Wolf, 1995: Radar and radiation properties of ice clouds. J. Appl. Meteor., 34, 2329-2345, https://doi.org/10.1175/1520-0450(1995) 034<2329:RARPOI $>2.0 . \mathrm{CO} ; 2$.

Atmospheric Radiation Measurement, 1994: Balloon sonde adjust. ARM Data Center, accessed 18 November 2019, https:// www.arm.gov/research/campaigns/sgp2011midlatcloud.

Aydin, K., and C. Tang, 1997: Relationships between IWC and polarimetric radar measurands at 94 and $220 \mathrm{GHz}$ for hexagonal columns and plates. J. Atmos. Oceanic Technol., 14, 1055-1063, https://doi.org/10.1175/1520-0426(1997)014<1055: RBIAPR $>2.0 . \mathrm{CO} ; 2$.

Bailey, M. P., and J. Hallett, 2009: A comprehensive habit diagram for atmospheric ice crystals: Confirmation from the laboratory, AIRS II, and other field studies. J. Atmos. Sci., 66, 2888-2899, https://doi.org/10.1175/2009JAS2883.1.

Baker, B. A., and R. P. Lawson, 2006: Improvement in determination of ice water content from two-dimensional particle imagery: Part I: Image to mass relationships. J. Appl. Meteor. Climatol., 45, 1282-1290, https://doi.org/10.1175/ JAM2398.1.

Bechini, R., and V. Chandrasekar, 2015: A semisupervised robust hydrometeor classification method for dual-polarization radar applications. J. Atmos. Oceanic Technol., 32, 22-47, https:// doi.org/10.1175/JTECH-D-14-00097.1.

Bowman, K. P., and C. R. Homeyer, 2017: GridRad-Threedimensional gridded NEXRAD WSR-88D radar data. National Center for Atmospheric Research Computational and Information Systems Laboratory, accessed 13 June 2018, https:// doi.org/10.5065/D6NK3CR7.

Brandes, E. A., G. Zhang, and J. Vivekanandan, 2002: Experiments in rainfall estimation with a polarimetric radar in a subtropical environment. J. Appl. Meteor., 41, 674-685, https://doi.org/ 10.1175/1520-0450(2002)041<0674:EIREWA > 2.0.CO;2. 
_- K. Ikeda, G. Zhang, M. Schonhuber, and R. M. Rasmussen, 2007: A statistical and physical description of hydrometeor distributions in Colorado snowstorms using a video disdrometer. J. Appl. Meteor. Climatol., 46, 634-650, https:// doi.org/10.1175/JAM2489.1.

Bukovčić, P., D. Zrnić, and G. Zhang, 2017: Winter precipitation liquid-ice phase transitions revealed with polarimetric radar and 2DVD observations in central Oklahoma. J. Appl. Meteor. Climatol., 56, 1345-1363, https://doi.org/10.1175/ JAMC-D-16-0239.1.

— A. Ryzhkov, D. Zrnić, and G. Zhang, 2018: Polarimetric radar relations for quantification of snow based on disdrometer data. J. Appl. Meteor. Climatol., 57, 103-120, https:// doi.org/10.1175/JAMC-D-17-0090.1.

Cressman, G. P., 1959: An operational objective analysis system. Mon. Wea. Rev., 87, 367-374, https://doi.org/10.1175/15200493(1959)087<0367:AOOAS > 2.0.CO;2.

Crosier, J., and Coauthors, 2014: Microphysical properties of cold frontal rainbands. Quart. J. Roy. Meteor. Soc., 140, 1257-1268, https://doi.org/10.1002/qj.2206.

Crum, T. D., and R. D. Alberty, 1993: The WSR-88D and the WSR-88D Operational Support Facility. Bull. Amer. Meteor. Soc., 74, 1669-1688, https://doi.org/10.1175/1520-0477(1993) 074<1669:TWATWO $>2.0 . \mathrm{CO} ; 2$.

Davis, C., and Coauthors, 2004: The Bow Echo and MCV Experiment: Observations and opportunities. Bull. Amer. Meteor. Soc., 85, 1075-1094, https://doi.org/10.1175/BAMS-85-8-1075.

Delanoe, J., A. Heymsfield, A. Protat, A. Bansemer, and R. Hogan, 2014: Normalized particle size distribution for remote sensing application. J. Geophys. Res. Atmos., 119, 4204-4227, https:// doi.org/10.1002/2013JD020700.

Dolan, B., and S. Rutledge, 2009: A theory-based hydrometeor identification algorithm for X-band polarimetric radars. J. Atmos. Oceanic Technol., 26, 2071-2088, https://doi.org/10.1175/ 2009JTECHA1208.1.

$\longrightarrow,-$ - S. Lim, V. Chandrasekar, and M. Thurai, 2013: A robust C-band hydrometeor identification algorithm and application to a long-term polarimetric radar dataset. J. Appl. Meteor. Climatol., 52, 2162-2186, https://doi.org/10.1175/JAMC-D-12-0275.1.

Fan, J., and Coauthors, 2015: Improving representation of convective transport for scale-aware parameterization: 1 . Convection and cloud properties simulated with spectral bin and bulk microphysics. J. Geophys. Res. Atmos., 120, 3485-3509, https://doi.org/10.1002/2014JD022142.

Fridlind, A. M., A. Ackerman, A. Grandin, F. Dezitter, M. Weber, J. Strapp, A. Korolev, and C. Williams, 2015: High ice water content at low radar reflectivity near deep convection-Part 1 : Consistency of in situ and remote-sensing observations with stratiform rain column simulations. Atmos. Chem. Phys., 15, 11 713-11 728, https://doi.org/10.5194/acp-15-11713-2015.

— , and Coauthors, 2017: Derivation of aerosol profiles for MC3E convection studies and use in simulations of the 20 May squall line case. Atmos. Chem. Phys., 17, 5947-5972, https:// doi.org/10.5194/acp-17-5947-2017.

Geerts, B., and Coauthors, 2017: The 2015 Plains Elevated Convection At Night field project. Bull. Amer. Meteor. Soc., 98, 767-786, https://doi.org/10.1175/BAMS-D-15-00257.1.

Griffin, E. M., T. J. Schuur, and A. V. Ryzhkov, 2018: A polarimetric analysis of ice microphysical processes in snow, using quasi-vertical profiles. J. Appl. Meteor. Climatol., 57, 31-50, https://doi.org/10.1175/JAMC-D-17-0033.1.

Han, B., and Coauthors, 2019: Cloud-resolving model intercomparison of an MC3E squall line case: Part II. Stratiform precipitation properties. J. Geophys. Res. Atmos., 124, 1090-1117, https://doi.org/10.1029/2018JD029596.

Heymsfield, A., Z. Wang, and S. Matrosov, 2005: Improved radar ice water content retrieval algorithms using coincident microphysical and radar measurements. J. Appl. Meteor., 44, 1391-1412, https://doi.org/10.1175/JAM2282.1.

- S. Matrosov, and N. Wood, 2016: Toward improving ice water content and snow-rate retrievals from radars. Part I: X and W bands, emphasizing CloudSat. J. Appl. Meteor. Climatol., 55, 2063-2090, https://doi.org/10.1175/JAMC-D-15-0290.1.

Hogan, R., M. Mittermaier, and A. Illingworth, 2006: The retrievals of ice water content from radar reflectivity factor and temperature and its use in evaluating a mesoscale model. J. Appl. Meteor. Climatol., 45, 301-317, https://doi.org/ 10.1175/JAM2340.1.

Homeyer, C. R., and K. P. Bowman, 2017: Algorithm description document for version 3.1 of the three-dimensional gridded NEXRAD WSR-88D radar (GridRad) dataset. University of Oklahoma-Texas A\&M University Tech. Rep., 23 pp., http:// gridrad.org/pdf/GridRad-v3.1-Algorithm-Description.pdf.

Houze, R. A., Jr., S. A. Rutledge, M. I. Biggerstaff, and B. F. Smull, 1989: Interpretation of Doppler weather radar displays of midlatitude mesoscale convective systems. Bull. Amer. Meteor. Soc., 70, 608-619, https://doi.org/10.1175/1520-0477(1989) 070<0608:IODWRD $>2.0$. CO;2.

Jameson, A., 1991: A comparison of microwave techniques for measuring rainfall. J. Appl. Meteor., 30, 32-54, https://doi.org/ 10.1175/1520-0450(1991)030<0032:ACOMTF > 2.0.CO;2.

Jensen, M. P., and Coauthors, 2016: The Midlatitude Continental Convective Clouds Experiment (MC3E). Bull. Amer. Meteor. Soc., 97, 1667-1686, https://doi.org/10.1175/BAMS-D-1400228.1 .

Klein, P., D. Turner, E. Smith, and J. Gebauer, 2016: Mobile PISA 1 OU/NSSL CLAMPS radiosonde data, version 1.0. UCAR/ NCAR Earth Observing Laboratory, accessed 5 September 2019, https://doi.org/10.5065/d6416vdh.

Kumjian, M. R., 2012: The impact of precipitation physical processes on the polarimetric radar variables. Ph.D. thesis, University of Oklahoma, $327 \mathrm{pp}$.

—, and A. V. Ryzhkov, 2008: Polarimetric signatures in supercell thunderstorms. J. Appl. Meteor. Climatol., 47, 1940-1961, https://doi.org/10.1175/2007JAMC1874.1.

— crophysical and kinematic structure of northeastern U.S. winter storms from dual-polarization Doppler radar. Mon. Wea. Rev., 145, 1033-1061, https://doi.org/10.1175/MWR-D15-0451.1.

—, A. V. Ryzhkov, H. D. Reeves, and T. J. Schuur, 2013: A dualpolarization radar signature of hydrometeor refreezing in winter storms. J. Appl. Meteor. Climatol., 52, 2549-2566, https://doi.org/10.1175/JAMC-D-12-0311.1.

Leroy, D., and Coauthors, 2017: Ice crystal sizes in high ice water content clouds. Part II: Statistics of mass diameter percentiles in tropical convection observed during the HAIC/HIWC project. J. Atmos. Oceanic Technol., 34, 117-136, https:// doi.org/10.1175/JTECH-D-15-0246.1.

Lim, S., V. Chandrasekar, and V. Bringi, 2005: Hydrometeor classification system using dual-polarization radar measurements: Model improvements and in-situ verification. IEEE Trans. Geosci. Remote Sens., 43, 792-801, https://doi.org/ 10.1109/TGRS.2004.843077.

Liu, C., and V. Chandrasekar, 2000: Classification of hydrometeors based on polarimetric radar measurements: Development of 
fuzzy logic and neuro-fuzzy systems, and in situ verification. J. Atmos. Oceanic Technol., 17, 140-164, https://doi.org/ 10.1175/1520-0426(2000)017<0140:COHBOP > 2.0.CO;2.

— and A. Illingworth, 2000: Toward more accurate retrievals of ice water content from radar measurements of clouds. J. Appl. Meteor., 39, 1130-1146, https://doi.org/10.1175/15200450(2000)039<1130:TMAROI >2.0.CO;2.

Maki, M., S.-G. Park, and V. Bringi, 2005: Effect of natural variations in rain drop size distributions on rain rate estimators of $3 \mathrm{~cm}$ wavelength polarimetric radar. J. Meteor. Soc. Japan, $\mathbf{8 3}$, 871-893, https://doi.org/10.2151/jmsj.83.871.

Marinescu, P. J., S. C. van den Heever, S. M. Saleeby, S. M. Kreidenweis, and P. J. De Mott, 2017: The microphysical roles of lower-tropospheric versus midtropospheric aerosol particles in mature-stage MCS precipitation. J. Atmos. Sci., 74, 3657-3678, https://doi.org/10.1175/JAS-D-16-0361.1.

Matrosov, S., R. Cifelli, P. Kennedy, S. Nesbitt, S. Rutledge, V. Bringi, and B. Martner, 2006: A comparative study of rainfall retrievals based on specific differential phase shifts at $\mathrm{X}$ - and S-band frequencies. J. Atmos. Oceanic Technol., 23, 952-963, https://doi.org/10.1175/JTECH1887.1.

$\longrightarrow,-$, and D. Gochis, 2013: Measurements of heavy convective rainfall in presence of hail in flood-prone areas using an X-band polarimetric radar. J. Appl. Meteor. Climatol., 52, 395407, https://doi.org/10.1175/JAMC-D-12-052.1.

—, A. Ryzhkov, J. Hardin, M. Shupe, M. Maahn, G. de Boer, and T. Uttal, 2019: Intercomparisons of CloudSat and groundbased radar measurements during satellite overpasses. 39th Int. Conf. on Radar Meteorology, Nara, Japan, Amer. Meteor. Soc., 11A-02, https://cscenter.co.jp/icrm2019/program/data/ abstracts/Session11A-02-2.pdf.

McFarquhar, G. M., J. A. Finlon, D. M. Stechman, W. Wu, R. C. Jackson, and M. Freer, 2018: University of Illinois/Oklahoma Optical Array Probe (OAP) processing software. Zenodo, https://doi.org/10.5281/zenodo.1285969.

Murphy, A. M., 2018: A microphysical analysis of the stratiform rain region of mesoscale convective systems using polarimetric radar and in situ aircraft measurements. M.S. thesis, School of Meteorology, University of Oklahoma, $155 \mathrm{pp}$.

National Weather Service, 1991: NOAA Next Generation Radar (NEXRAD) level 2 base data. NOAA National Centers for Environmental Information, accessed 3 November 2017, https://doi.org/10.7289/V5W9574V.

Nguyen, C. M., M. Wolde, and A. Korolev, 2019: Determination of ice water content (IWC) in tropical convective clouds from X-band dual-polarization airborne radar. Atmos. Meas. Tech., 12, 5897-5911, https://doi.org/10.5194/amt-12-5897-2019.

Park, H., A. V. Ryzhkov, D. S. Zrnić, and K. Kim, 2009: The hydrometeor classification algorithm for the polarimetric WSR88D: Description and application to an MCS. Wea. Forecasting, 24, 730-748, https://doi.org/10.1175/2008WAF2222205.1.

Protat, A., and Coauthors, 2016: The measured relationship between ice water content and cloud radar reflectivity in tropical convective clouds. J. Appl. Meteor. Climatol., 55, 1707-1729, https://doi.org/10.1175/JAMC-D-15-0248.1.

Ryzhkov, A., and D. Zrnić, 1996: Assessment of rainfall measurement that uses specific differential phase. J. Appl. Meteor., 35, 2080-2090, https://doi.org/10.1175/1520-0450(1996)035<2080: AORMTU>2.0.CO;2.

— , and — 1998: Discrimination between rain and snow with a polarimetric radar. J. Appl. Meteor., 37, 1228-1240, https://doi.org/ 10.1175/1520-0450(1998)037<1228:DBRASW>2.0.CO;2.
— and - 2019: Radar Polarimetry for Weather Observations. Springer International Publishing, 486 pp.

,-- , and B. A. Gordon, 1998: Polarimetric method for ice water content determination. J. Appl. Meteor., 37, 125-134, https://doi.org/10.1175/1520-0450(1998)037<0125:PMFIWC> 2.0.CO;2.

- D. W. Burgess, D. S. Zrnić, T. Smith, and S. E. Giangrande, 2002: Polarimetric analysis of a 3 May 1999 tornado. 21st Conf. on Severe Local Storms, San Antonio, TX, Amer. Meteor. Soc., 14.2, https://ams.confex.com/ams/SLS_WAF_NWP/techprogram/ paper_47348.htm.

, S. E. Giangrande, V. M. Melnikov, and T. J. Schuur, 2005a: Calibration issues of dual-polarization radar measurements. J. Atmos. Oceanic Technol., 22, 1138-1155, https://doi.org/ 10.1175/JTECH1772.1.

,-- , and T. J. Schuur, 2005b: Rainfall estimation with a polarimetric prototype of WSR-88D. J. Appl. Meteor., 44, 502-515, https://doi.org/10.1175/JAM2213.1.

—, T. J. Schuur, D. W. Burgess, and D. S. Zrnić, 2005c: Polarimetric tornado detection. J. Appl. Meteor., 44, 557-570, https://doi.org/10.1175/JAM2235.1.

— , P. Zhang, H. Reeves, M. Kumjian, T. Tschallener, S. Troemel, and C. Simmer, 2016: Quasi-vertical profiles-A new way to look at polarimetric radar data. J. Atmos. Oceanic Technol., 33, 551-562, https://doi.org/10.1175/JTECH-D-15-0020.1.

_ - and Coauthors, 2017: Estimation of depolarization ratio using weather radars with simultaneous transmission/reception. J. Appl. Meteor. Climatol., 56, 1797-1816, https://doi.org/ 10.1175/JAMC-D-16-0098.1.

— P. Bukovcic, A. Murphy, P. Zhang, and G. McFarquhar, 2018: Ice microphysical retrievals using polarimetric radar data. 10th European Conf. on Radar in Meteorology and Hydrology, Wageningen, Netherlands, KNMI, 40, projects.knmi.nl/erad2018/ERAD2018-extended-abstract-040.pdf.

Sachidananda, M., and D. S. Zrnić, 1987: Rain rate estimates from differential polarization measurements. J. Atmos. Oceanic Technol., 4, 588-598, https://doi.org/10.1175/1520-0426(1987) 004<0588:RREFDP $>2.0 . \mathrm{CO} ; 2$.

Sassen, K., 1987: Ice cloud content from radar reflectivity. J. Climate Appl. Meteor., 26, 1050-1053, https://doi.org/10.1175/15200450(1987)026<1050:ICCFRR > 2.0.CO;2.

Skofronick-Jackson, G., M. Kulie, L. Milani, S. J. Munchak, N. B. Wood, and V. Levizzani, 2019: Satellite estimation of falling snow: A Global Precipitation Measurement (GPM) Core Observatory perspective. J. Appl. Meteor. Climatol., 58, 1429-1448, https://doi.org/10.1175/JAMC-D-18-0124.1.

Snyder, J. C., and A. V. Ryzhkov, 2015: Automated detection of polarimetric tornadic debris signatures using a hydrometeor classification algorithm. J. Appl. Meteor. Climatol., 54, 18611870, https://doi.org/10.1175/JAMC-D-15-0138.1.

Stanford, M., A. Warble, E. Zipser, J. Strapp, A. Leroy, A. Schwarzenboeck, R. Potts, and A. Protat, 2017: A ubiquitous ice size bias in simulations of tropical deep convection. Atmos. Chem. Phys., 17, 9599-9621, https://doi.org/10.5194/acp17-9599-2017.

Straka, J., 1996: Hydrometeor fields in a supercell storm as deduced from dual-polarization radar. 18th Conf. on Severe Local Storms, San Francisco, CA, Amer. Meteor. Soc., 551-554.

— and contents from multiparameter radar data. 26th Int. Conf. on Radar Meteorology, Norman, OK, Amer. Meteor. Soc., 513-516. , - - and A. V. Ryzhkov, 2000: Bulk hydrometeor classification and quantification using polarimetric radar data: Synthesis 
of relations. J. Appl. Meteor., 39, 1341-1372, https://doi.org/ 10.1175/1520-0450(2000)039<1341:BHCAQU >2.0.CO;2.

Strapp, J. W., and Coauthors, 2016: The high ice water content (HIWC) study of deep convective clouds: Report on science and technical plan. Federal Aviation Administration Rep. DOT/FAA/TC-14/31, 105 pp., http://www.tc.faa.gov/its/worldpac/ techrpt/tc14-31.pdf.

Sulia, K. J., and M. R. Kumjian, 2017: Simulated polarimetric fields of ice vapor growth using the adaptive habit model. Part II: A case study from the FROST experiment. Mon. Wea. Rev., 145 , 2303-2323, https://doi.org/10.1175/MWR-D-16-0062.1.

Tabary, P., A. Boumahmoud, H. Andrieu, R. Thompson, A. Illingworth, E. LeBouar, and J. Testud, 2011: Evaluation of two "integrated" polarimetric quantitative precipitation estimation (QPE) algorithms at C band. J. Hydrol., 405, 248-260, https://doi.org/10.1016/ j.jhydrol.2011.05.021.

Thompson, E., S. Rutledge, B. Dolan, M. Thurai, and V. Chandrasekar, 2018: Dual-polarization radar rainfall estimation over tropical oceans. J. Appl. Meteor. Climatol., 57, 755-775, https://doi.org/ 10.1175/JAMC-D-17-0160.1.

Tian, J., X. Dong, B. Xi, J. Wang, C. R. Homeyer, G. M. McFarquhar, and J. Fan, 2016: Retrievals of ice cloud microphysical properties of deep convective systems using radar measurements. J. Geophys. Res. Atmos., 121, 10 820-10839, https://doi.org/10.1002/2015JD024686.

Tobin, D. M., and M. R. Kumjian, 2017: Polarimetric radar and surface-based precipitation-type observations of ice pellet to freezing rain transitions. Wea. Forecasting, 32, 2065-2082, https://doi.org/10.1175/WAF-D-17-0054.1.

Trömel, S., A. V. Ryzhkov, P. Zhang, and C. Simmer, 2014: Investigations of backscatter differential phase in the melting layer. J. Appl. Meteor. Climatol., 53, 2344-2359, https://doi.org/ 10.1175/JAMC-D-14-0050.1.

,,-- K. Diederich, K. Muhlbauer, S. Kneifel, J. Snyder, and C. Simmer, 2017: Multisensor characterization of mammatus. Mon. Wea. Rev., 145, 235-251, https://doi.org/10.1175/MWRD-16-0187.1.

Van Den Broeke, M. S., and S. T. Jauernic, 2014: Spatial and temporal characteristics of polarimetric tornadic debris signatures. J. Appl. Meteor. Climatol., 53, 2217-2231, https:// doi.org/10.1175/JAMC-D-14-0094.1.

—, D. M. Tobin, and M. R. Kumjian, 2017: Polarimetric radar observations of precipitation type and rate from the 2-3 March 2014 winter storm in Oklahoma and Arkansas. Wea. Forecasting, 31, 1179-1196, https://doi.org/10.1175/WAF-D-16-0011.1.

van Lier-Walqui, M., and Coauthors, 2016: On polarimetric radar signatures of deep convection for model evaluation: Columns of specific differential phase observed during MC3E. Mon. Wea. Rev., 144, 737-758, https://doi.org/10.1175/MWR-D-15-0100.1.

Vivekanandan, J., V. N. Bringi, M. Hagen, and P. Meischner, 1994: Polarimetric radar studies of atmospheric ice particles. IEEE Trans. Geosci. Remote Sens., 32, 1-10, https://doi.org/10.1109/ 36.285183 .

Zhang, G., 2017: Weather Radar Polarimetry. CRC Press, 304 pp.

Zrnić, D. S., and A. V. Ryzhkov, 1999: Polarimetry for weather surveillance radars. Bull. Amer. Meteor. Soc., 80, 389-406, https://doi.org/10.1175/1520-0477(1999)080<0389:PFWSR > 2.0.CO;2.

,,-- J. Straka, Y. Liu, and J. Vivekanandan, 2001: Testing a procedure for automatic classification of hydrometeor types. J. Atmos. Oceanic Technol., 18, 892-913, https://doi.org/ 10.1175/1520-0426(2001)018<0892:TAPFAC >2.0.CO;2. 